Impact of Time Resolution on the Projected Rates of System Penetration by Intermittent Generation Technologies

A. Lamont and T. Wu

July 18, 2006 
This document was prepared as an account of work sponsored by an agency of the United States Government. Neither the United States Government nor the University of California nor any of their employees, makes any warranty, express or implied, or assumes any legal liability or responsibility for the accuracy, completeness, or usefulness of any information, apparatus, product, or process disclosed, or represents that its use would not infringe privately owned rights. Reference herein to any specific commercial product, process, or service by trade name, trademark, manufacturer, or otherwise, does not necessarily constitute or imply its endorsement, recommendation, or favoring by the United States Government or the University of California. The views and opinions of authors expressed herein do not necessarily state or reflect those of the United States Government or the University of California, and shall not be used for advertising or product endorsement purposes

This work was performed under the auspices of the U.S. Department of Energy by University of California, Lawrence Livermore National Laboratory under Contract W7405-Eng-48. 


\title{
Impact of Time Resolution on the Projected Rates of System Penetration by Intermittent Generation Technologies
}

\author{
Alan Lamont and Tony $\mathrm{Wu}$ \\ Systems and Decision Sciences Section \\ Lawrence Livermore National Laboratory
}

\section{Introduction}

To hedge against the limited resources of fossil fuels and to reduce the emissions of green house gases, it is expected that our future electricity system will include more intermittent technologies, including wind and PV. To better understand how to develop energy systems that rely on intermittents, systems models are used to assess the cost at which intermittents become competitive, the degree of penetration as their costs are reduced, their impact on the optimal structure of the balance of the system, and their affect on total system costs.

Modeling approaches designed for dispatchable technologies are not entirely appropriate for modeling intermittent technologies, since they, naturally, assume that generation can always be dispatched to meet demand. Intermittent generation cannot be dispatched - its output varies from hour to hour and from day to day on its own schedule, heedless to system needs. This research assesses the difference in results associated with the different approaches to modeling intermittency. The analyses compare cases using the hourly loads and intermittent generation patterns, cases in which the loads and generation were averaged over several hours, and cases in which the loads and/or the generation were represented by the annual averaging scheme used in the National Energy Modeling System developed by the Energy Information Administration.

Three significant characteristics of an intermittent generator are the average power production (capacity factor), the coincidence of its power production and loads, and the variation in the magnitude of its power production. Economic models of the energy system represent these characteristics with differing degrees of accuracy. It is expected that different representations of the characteristics of an intermittent generator will give different answers to the sorts of questions posed above. This research assesses the magnitude and types of errors that are introduced by not representing the characteristics of the intermittents accurately.

The most accurate representation of an intermittent generator uses its actual output from moment to moment. Here we use a one hour resolution over a full year of generation as the base case. This captures the variations from hour to hour and day-to day. However, some energy modeling systems are based on a load duration curve approach for characterizing the variation in energy demand. This is quite suitable for dispatchable technologies since the generators can always be dispatched to meet the load whenever it occurs. When an intermittent generator is represented in this structure, it is represented as having a constant output equal to its capacity factor over long intervals 
(many hours). This approach captures the capacity factor of the intermittent and to some extent it can capture the coincidence of generation and demand, but does not capture the effect of the short term variations in output.

In this paper, we evaluate the impacts of time resolution on the economic evaluation of wind and solar PV within a simple energy system. We assess the penetration of each intermittent generator as its cost is decreased. At the same time, the model optimally readjusts the capacities and dispatch of the conventional generators as the intermittent technology penetrates. This investigation compares the trajectories of intermittent penetration under a several different representations of intermittent generation and demand.

In the following sections, we first discuss the approach to analysis, for both the load duration curve approach to representing intermittent generation and several averaging schemes. We then present results and conclusions.

\section{Approach to analysis}

A series of analyses were made using a simple model of an electric generation system (see below). This model can represent the patterns of electricity demands and intermittent generation at wide range of time resolutions and patterns over a full year. Given the capital and operating costs of all the generators, the patterns of electricity demand, and the patterns of intermittent generation, the model finds the cost-minimizing generation capacities and dispatch. In each analysis, the cost of the intermittent technology was reduced in steps to observe the penetration of the technology and the changes in the structure and operation of the other generators in the system. The following sections describe the system model and the patterns of demand and generation used in the analyses.

\section{Energy system model}

The assessments were made using the simple energy system shown in Figure 1. The demand node at the top represents the demands at whatever time resolution is being studied. The demand is met by a combination of peaker, intermediate, and base load technologies, along with either wind or PV, depending on the case analyzed. The model uses the META-Net (Lamont 1994) modeling system which optimizes the dispatch of the generators each hour and the capacities of each generator so as to minimize total system cost. The generators are dispatched each hour in merit order. 
Figure 1: The energy system

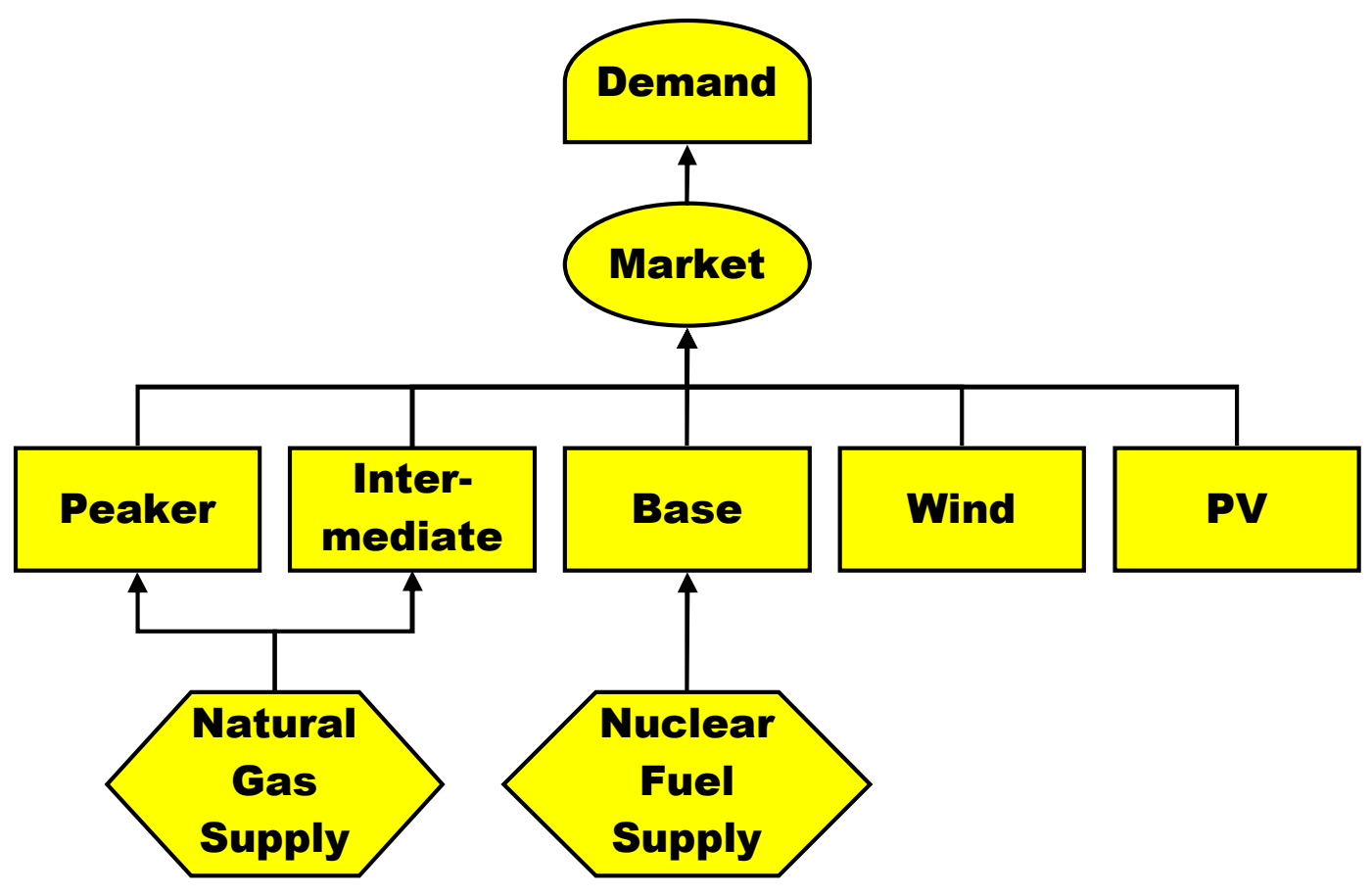

This study analyzes the penetration of wind and PV and the optimal system structure as a function of the cost of wind and PV. This gives us the cost that will initiate penetration, the trajectory of penetration, and the changes in capacities of the other generators.

We use the META-Net (Lamont 1994) model which is able to represent the generation and load at any level of time resolution. To represent the actual pattern we have run the model with actual hourly load and generation profiles over a full year. To investigate the impacts of simple averaging, we make runs using: the actual hourly data, data that has been averaged over intervals during the day (local average, each day is different), data that is averaged using the NEMS scheme. In order to separate the effects of averaging and from the effects of averaging intermittent generations, some runs have been made with averaged load, while others are made with hourly loads.

The analysis examines penetration under several different sets of assumptions about load and generation patterns. By examining the effects of several different variations, we are better able to identify the features of an averaging scheme that distort the results. This should allow us to study (1) actual hourly loads and generation, (2) local average generation patterns, (3) aggregated generation over segments of each day of each season as in NEMS.

\section{Cost and financial assumptions}

For the most part, our costs and financial assumptions are based on EIA AEO 
- Costs of intermittent generators were varied from a starting point of today's cost, based on AEO

- Life time of intermittent generators are based on AEO

- Interest rate is $10 \%$

- Natural gas price is $\$ 6 / \mathrm{mmBTU}$

- Efficiencies, lifetimes, and operating costs of dispatchable generators followed AEO

- Wind based on Tehachapis in California

- PV based on panel located in Sacramento elevated at latitude and pointed South

\section{Hourly data and averaging schemes}

To assess the impact of time resolution we have structured the data with three different cases. The first case uses the original hour-by-hour data. The second case averages the data over four-hour periods ( 6 periods per day). This is referred to as the "local average" case. The average value over each four hour period is computed and applied to the entire four hour period. In this case, the data for each day of the year are different depending on the data for that particular day. The last case is the "aggregated" case which follows the conventions of the load duration curve patterns used in the National Energy Modeling System. In the aggregated case, the data are averaged for different periods of the day and for each season of the year. For example, the energy demands for all spring mornings have the same value.

Figure 2 shows the hourly electricity demand over one year. This has been normalized to a peak demand of $1 \mathrm{~kW}$. Figure 3 and Figure 4 are actual wind and PV production factors over one year. These are also normalized so that a value of 1.0 means the generator is delivering its full rated output.

Figure 2: Hourly Normalized Electricity Demand over full year

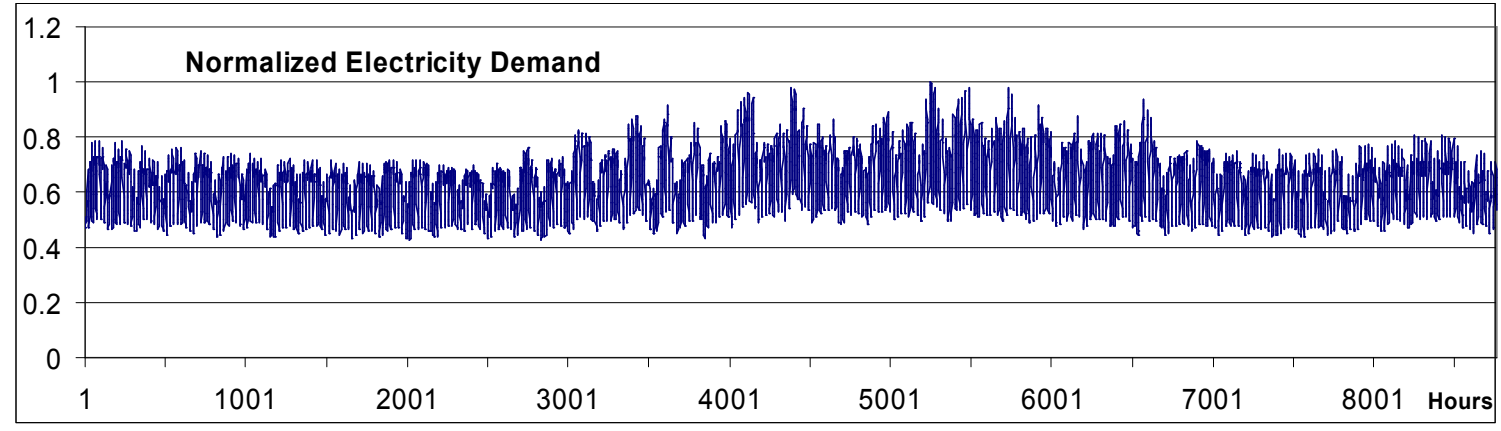


Figure 3: Hourly Actual Wind Production Factor

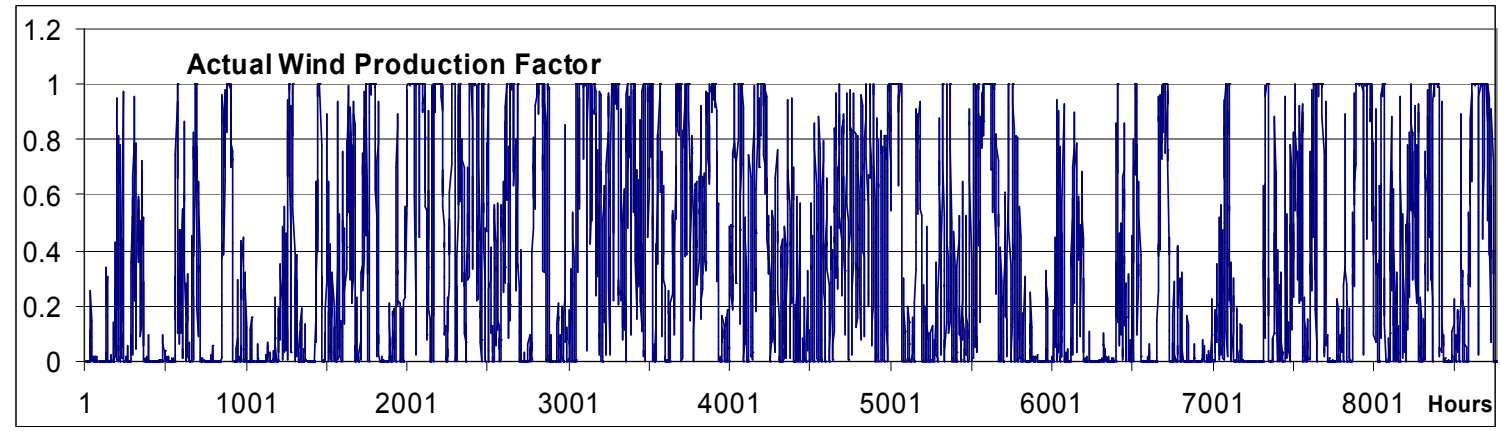

Figure 4: Hourly Actual PV Production Factor

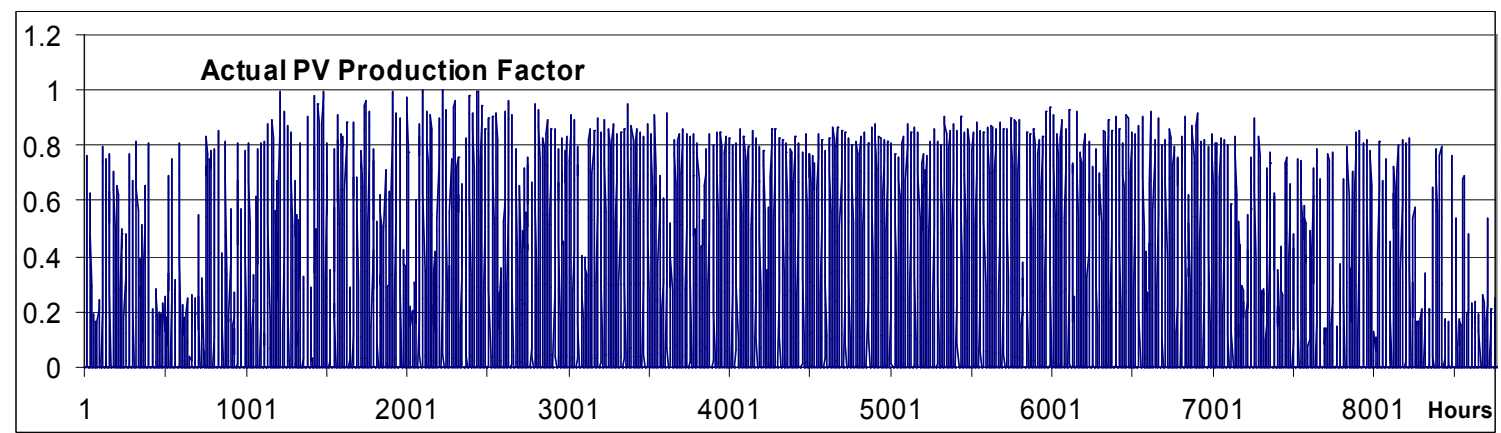

The hour-by-hour data is shown in the figures above. The local averaging data is fairly straightforward. The results of the local averaging are illustrated in Figure 5 and Figure 6. The following paragraphs discuss the averaging scheme used to represent the NEMS approach. 
Figure 5: Comparison of actual load and wind generation under various averaging schemes

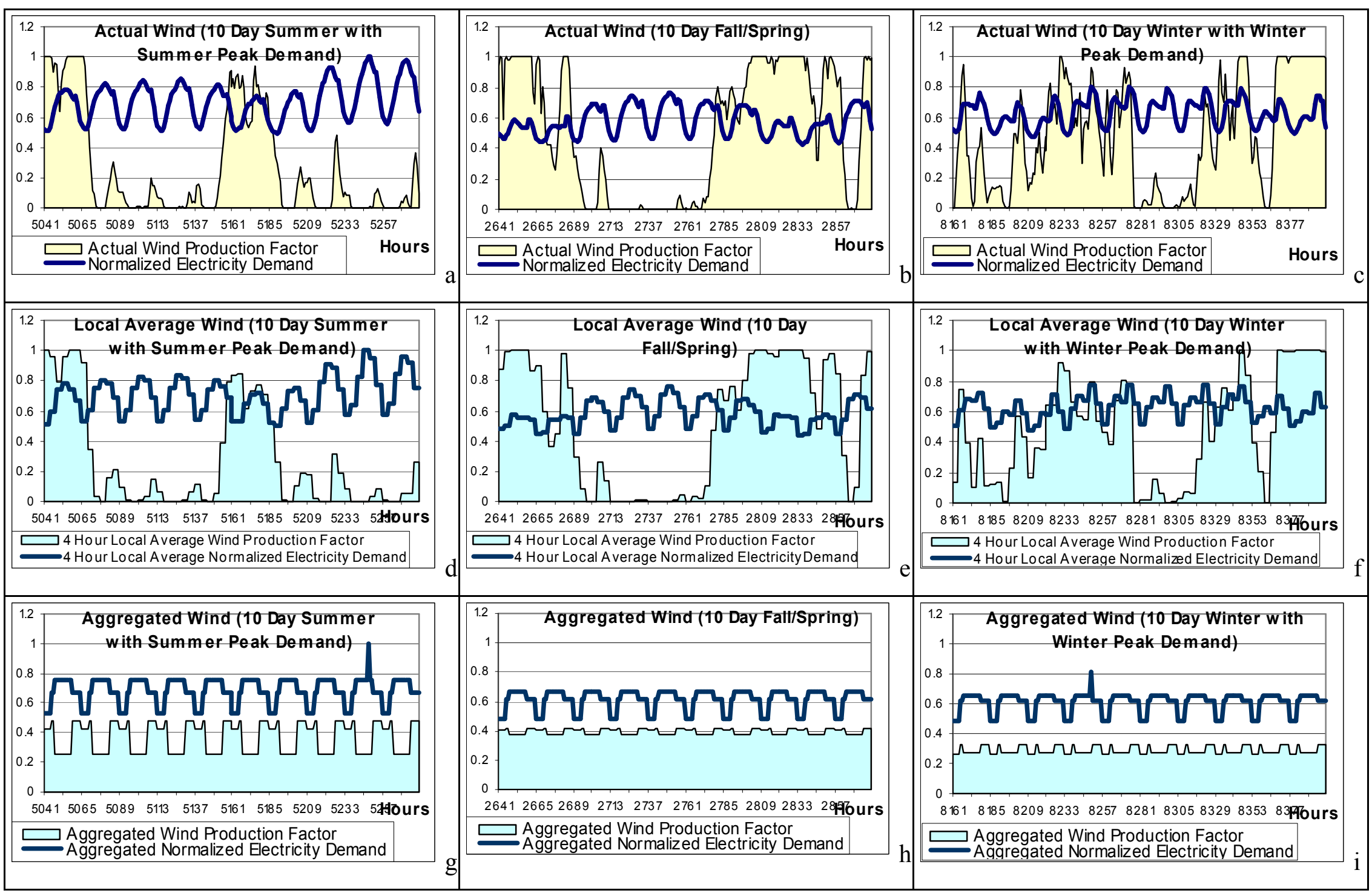


Figure 6: Comparison of load and PV generation under various averaging schemes

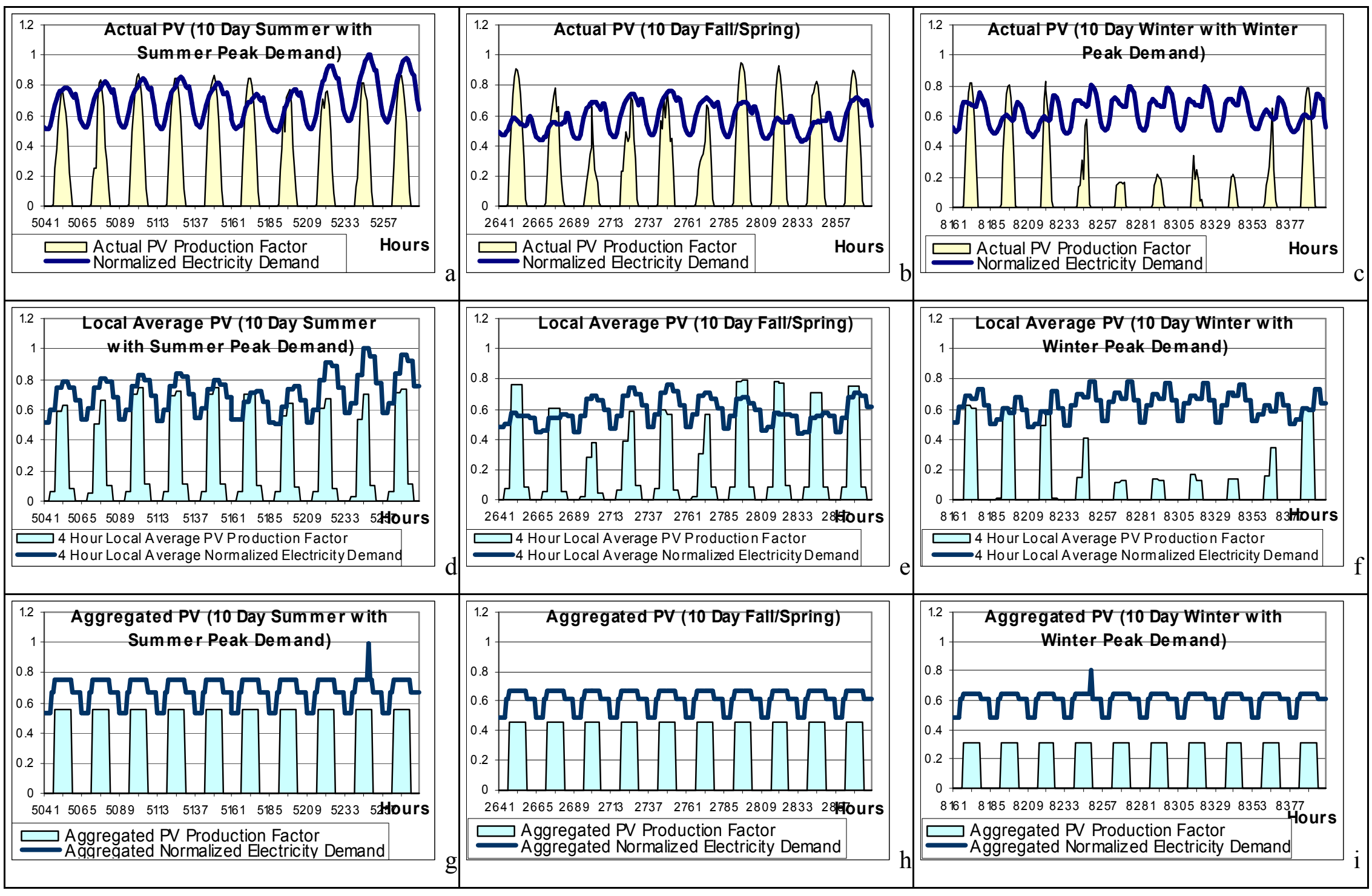


The optimal analysis of an electric generation system finds the optimal capacities of each type of generator. A range of generator types is available when designing a system. In our model we include "baseload" generators with high capital costs and low operating costs, "intermediate" generators with moderate capital costs and operating costs, and "peak" generators having low capital costs but high operating costs.

The optimal mixture of these plants depends on the pattern of demands over the year. For dispatchable technologies, the exact pattern of demands is not important (as a first order approximation ${ }^{1}$ ). Only the frequency of different levels of demands is important since a dispatchable plant can be dispatched to meet the demand. Recognizing this, many models use a "load duration curve" or "LDC" to represent these variations. The LDC is a cumulative probability distribution over the system load-it represents the fraction of the year that the load is at or above any given level. When analyzing systems with dispatchable technologies, this is adequate.

A typical scheme is used by the National Energy Modeling System (NEMS) (EIA 2001). Here the year is divided up into 11 "typical" types of hours: night, day, and evening for each the winter, Spring/Fall, and summer seasons. In addition the summer and winter peaks hours are included. Table 1 is the definition of seasonal time-of-day load segments used in NEMS.

${ }^{1}$ This is an approximation for a first order analysis of the system. In real systems plants cannot necessarily be brought on line at will. Many plants must be brought up to full output slowly over several hours. For these plants the exact order of demands is important. However, for the purposes of this type of analysis, the error is very small. 
Table 1: Definition of Seasonal/Time-of-Day Load Segments

\begin{tabular}{|c|c|c|}
\hline Load Group & Months & Hours \\
\hline $\begin{array}{l}\text { Summer } \\
\text { Daytime }\end{array}$ & "June - September & 7:00 a.m. - 6:00 p.m. \\
\hline $\begin{array}{l}\text { Summer } \\
\text { Morning/Evening }\end{array}$ & June - September & $\begin{array}{l}\text { 5:00 a.m. - 7:00 a.m., } \\
\text { 6:00 p.m. - 12:00 p.m. }\end{array}$ \\
\hline $\begin{array}{l}\text { Summer } \\
\text { Night }\end{array}$ & June - September & 12:00 p.m. - 5:00 a.m. \\
\hline $\begin{array}{l}\text { Winter } \\
\text { Daytime }\end{array}$ & December - March & 7:00 a.m. - 6:00 p.m. \\
\hline $\begin{array}{l}\text { Winter } \\
\text { Morning/Evening }\end{array}$ & December - March & $\begin{array}{l}\text { 5:00 a.m. - 7:00 a.m., } \\
\text { 6:00 p.m. - 12:00 p.m. }\end{array}$ \\
\hline $\begin{array}{l}\text { Winter } \\
\text { Night }\end{array}$ & December - March & 12:00 p.m. - 5:00 a.m. \\
\hline $\begin{array}{l}\text { Fall/Spring } \\
\text { Daytime }\end{array}$ & $\begin{array}{l}\text { April - May, } \\
\text { October - November }\end{array}$ & 7:00 a.m. - 6:00 p.m. \\
\hline $\begin{array}{l}\text { Fall/Spring } \\
\text { Morning/Evening }\end{array}$ & $\begin{array}{l}\text { April - May, } \\
\text { October - November }\end{array}$ & $\begin{array}{l}\text { 5:00 a.m. - 7:00 a.m., } \\
\text { 6:00 p.m. - 12:00 p.m. }\end{array}$ \\
\hline $\begin{array}{l}\text { Fall/Spring } \\
\text { Night }\end{array}$ & $\begin{array}{l}\text { April - May, } \\
\text { October - November }\end{array}$ & 12:00 p.m. - 5:00 a.m. \\
\hline
\end{tabular}

These can be ordered as a load duration curve as illustrated in Figure 7. 
Figure 7: Load Duration Curve with Time-of-Day and Seasonal Load Segmentation

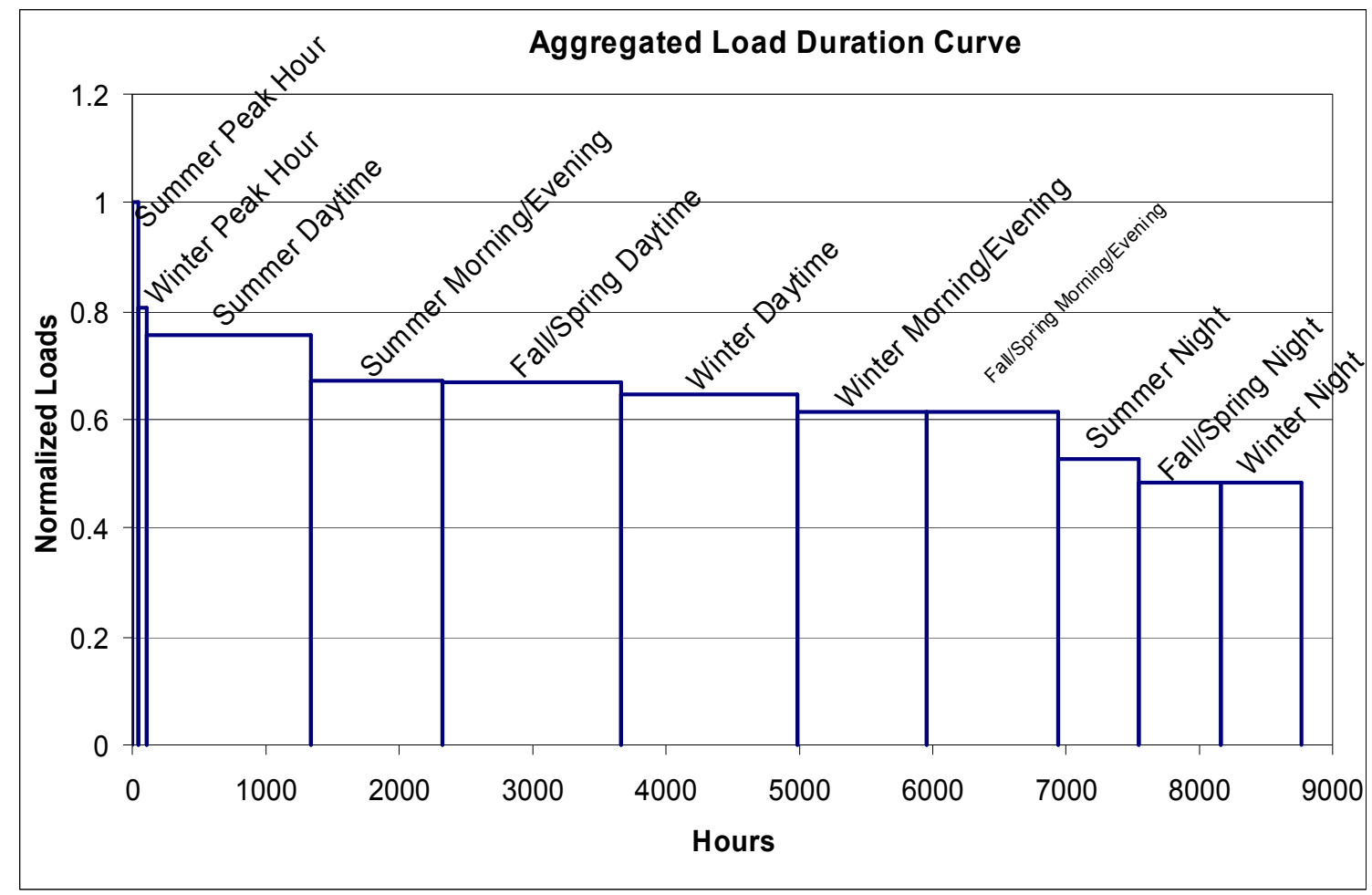

Intermittent generators are represented in this scheme by computing their average power during each of these time periods. For example, $\mathrm{PV}$ output at night is always 0 . It is low in the evening and highest during the day. This representation does capture some of the variation in the generator output and it represents its variation in output for each time of day and season of the year. However, it does not represent the variation that occurs from hour to hour within these time segments. A generator that produces at full capacity $20 \%$ of the time and at $0 \%$ the rest of the time is represented as producing $20 \%$ all of the time. The high peaks in output are important for assessing intermittents at significant levels of penetration since they affect the marginal cost of generation in some hours, which, in turn, affects the economics of the other generators on the system. As we will see later, the LDC approach generally tends to over-value the intermittent since it represents the intermittent as behaving better than it actually does. This approach does capture some of the coincidence between system loads and intermittent output- $\mathrm{PV}$ is represented as generating during the day when average loads are higher. Nonetheless, there is substantial variation in loads within these segments and substantial variation in the intermittent generation. The LDC approach does not capture this. Of course, the question is how much of an error is there and to what extent does that bias the results from the model. This analysis uses a model that can model with very high time resolution - a maximum of 8760 one hour periods per year is used in this study - to compare the results that are obtained with different levels of time resolution.

To view these patterns more closely, we plot three representative ten day hourly electricity demand and actual wind production factor in Figure 5 and for ten day summer with summer peak electricity demand, ten day fall and spring and ten day winter with 
winter peak electricity demand. We plot the local average of electricity demand and wind production factor over 4 hour intervals and the aggregated electricity demand and wind production factor as in NEMS. Similar plots for PV are depicted in Figure 6.

We plot three ten day periods for wind and three for PV. One period falls in summer with summer peak demand, one is in spring and the third is in winter with the winter peak demand. For each period, three versions are shown: one with actual demands and generation, one with a local averaging (over 4 hour periods) and the last with the NEMS aggregating scheme. One set of plots is shown for wind (Figure 5) and one for PV (Figure 6).

We note that the actual wind generation power ranges from full capacity to 0 in all seasons of the year. When the wind power is at full capacity, it will displace other generation on the system. This tends to reduce the marginal cost of generation on the system and affects the optimal capacities of other generators (See Lamont 2005). Both the hour-by-hour representation and the local averaging preserve this behavior. However, the aggregated averaging does not. The wind power falls within a narrow range, never reaching more than about half its rated capacity and never falling below about $25 \%$ of rated capacity. During the spring and winter, the wind is represented as a very stable, steady generator, much like a baseload generator. As we will see in the analyses below, this results in a high penetration of the wind generator.

The actual PV generation tends to match the actual loads, although we note that it has its peak output a few hours earlier than the actual peak load (note the PV panels are assumed to be pointed due South in this example). When the loads and the PV are aggregated in the LDC scheme, they match exactly since they are averaged over the same hours of the day. Similar to the case of the wind generator, this gives an unrealistically high value to the PV generator.

\section{Results}

This section first presents results for system dispatch under the different schemes. This provides some of the essential background for interpreting the subsequent results. We then discuss penetration of wind and PV under the different schemes for representing generation and demand patterns. The results show that there is little difference between the result using hourly data and local average data (averaged over four hour time period). Consequently, we only depict the results using the hourly data in this report.

\section{System dispatch}

Figure 8 illustrates the case with relatively high wind capacity and shows the dispatch of the generators over a ten day period in the summer, which includes the summer peak electricity demand. Figure 6a is the result by using true data for both the electricity and wind. Figure $6 \mathrm{~b}$ is the result by using the true electricity demand and aggregated wind supply. Figure $6 \mathrm{c}$ is the result by using the aggregated data for both electricity demand and wind supply. 
Figure 8: System dispatch, generation, and loads under different averaging schemes for the case of wind generation

\section{a: Hour-by-hour representation of wind generation and load}

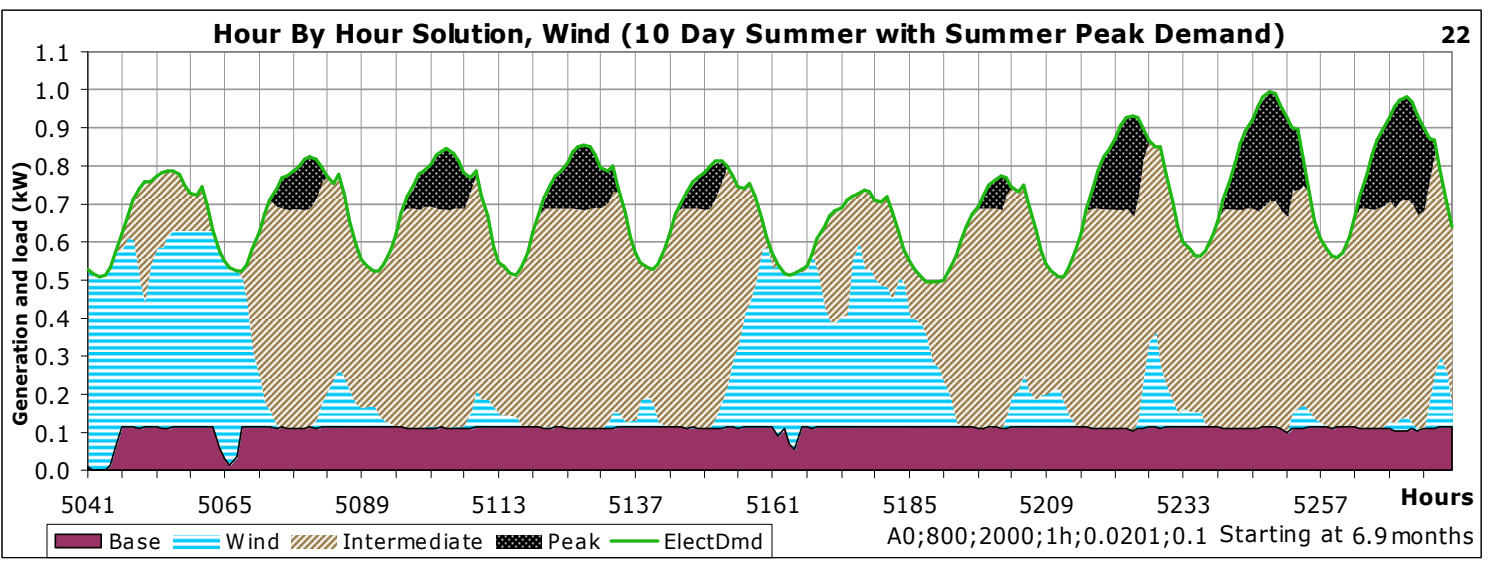

b: aggregated wind generation with hour-by-hour loads

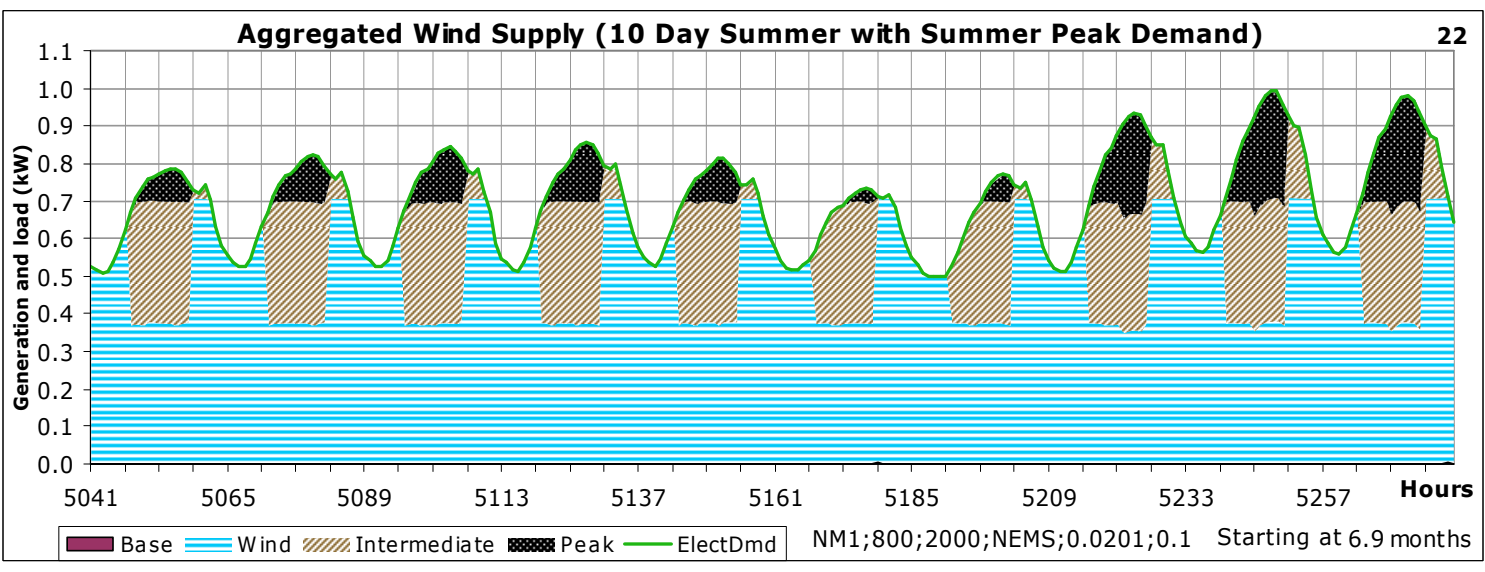

c: aggregated wind generation and loads

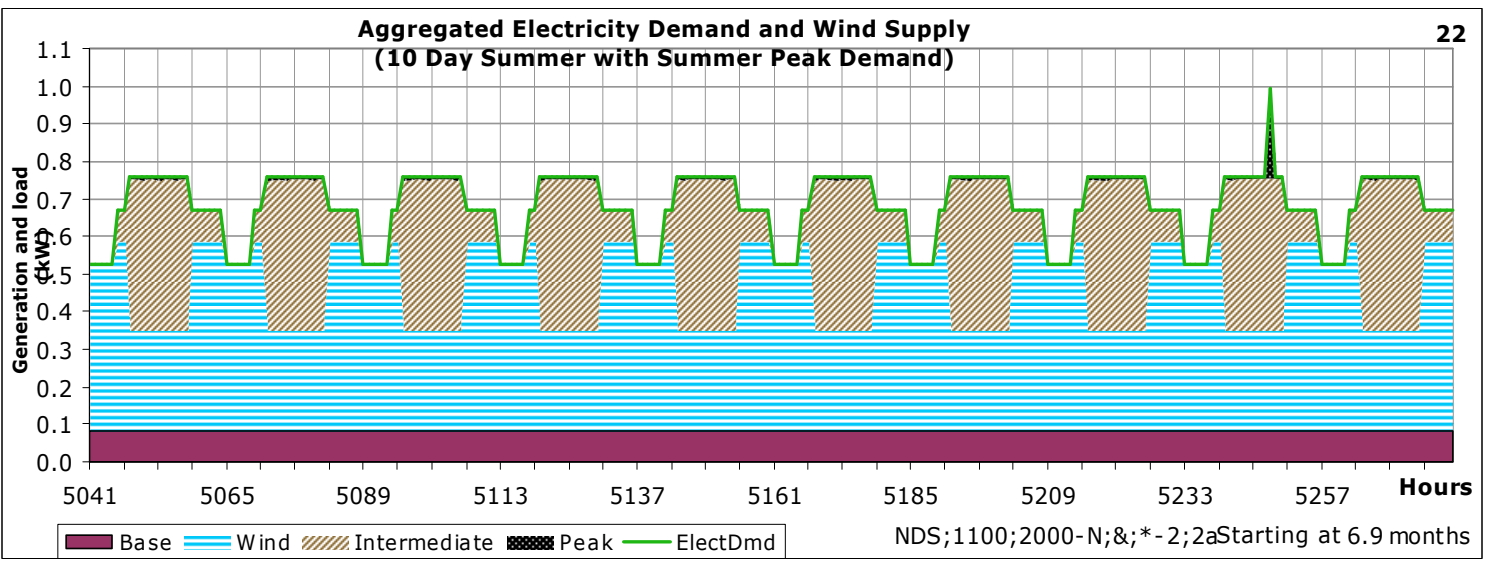


Figure 9 illustrates the solution of ten day summer time period with summer peak electricity demand when the capital cost of PV is much cheaper than wind, that is, we rule out the wind from the system. Figure $7 \mathrm{a}$ is the result by using true data for both the electricity and PV. Figure $7 \mathrm{~b}$ is the result by using the true electricity demand and aggregated PV supply. Figure $6 \mathrm{c}$ is the result by using the aggregated data for both electricity demand and PV supply.

Figure 9: System dispatch, generation, and loads under different averaging schemes for the case of PV generation

\section{a: hour-by-hour representation of loads and PV generation}

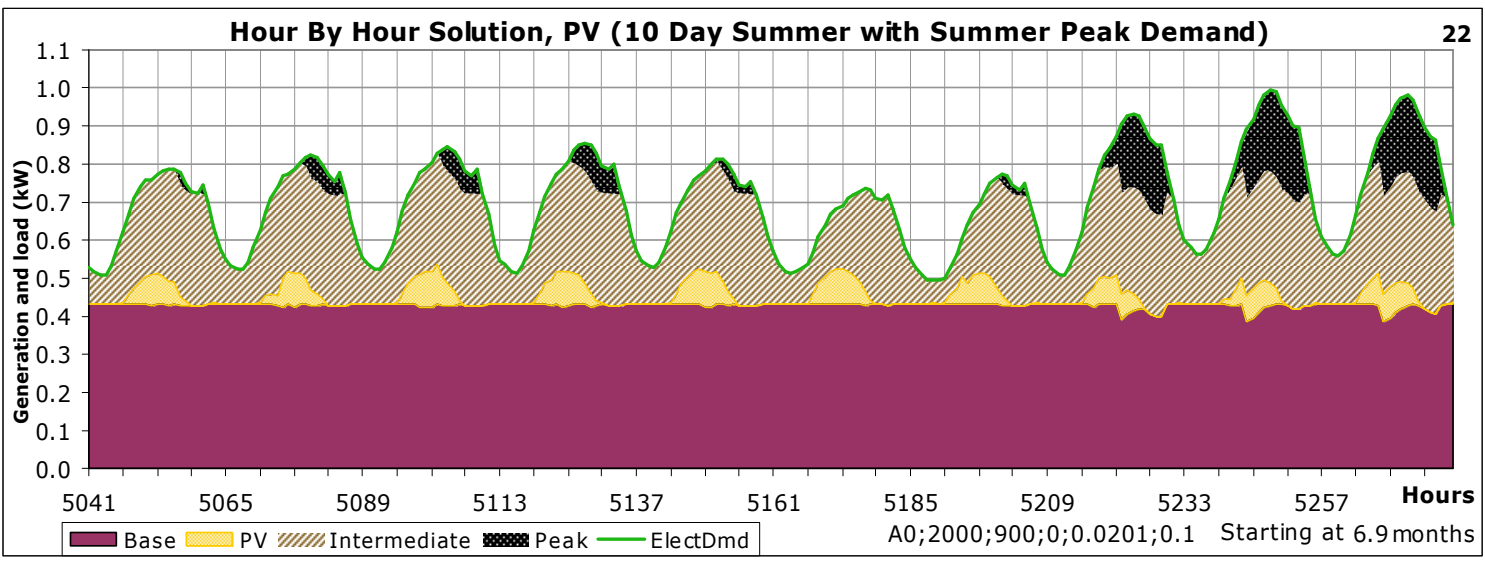

\section{b: aggregated PV generation with hour-by-hour loads}

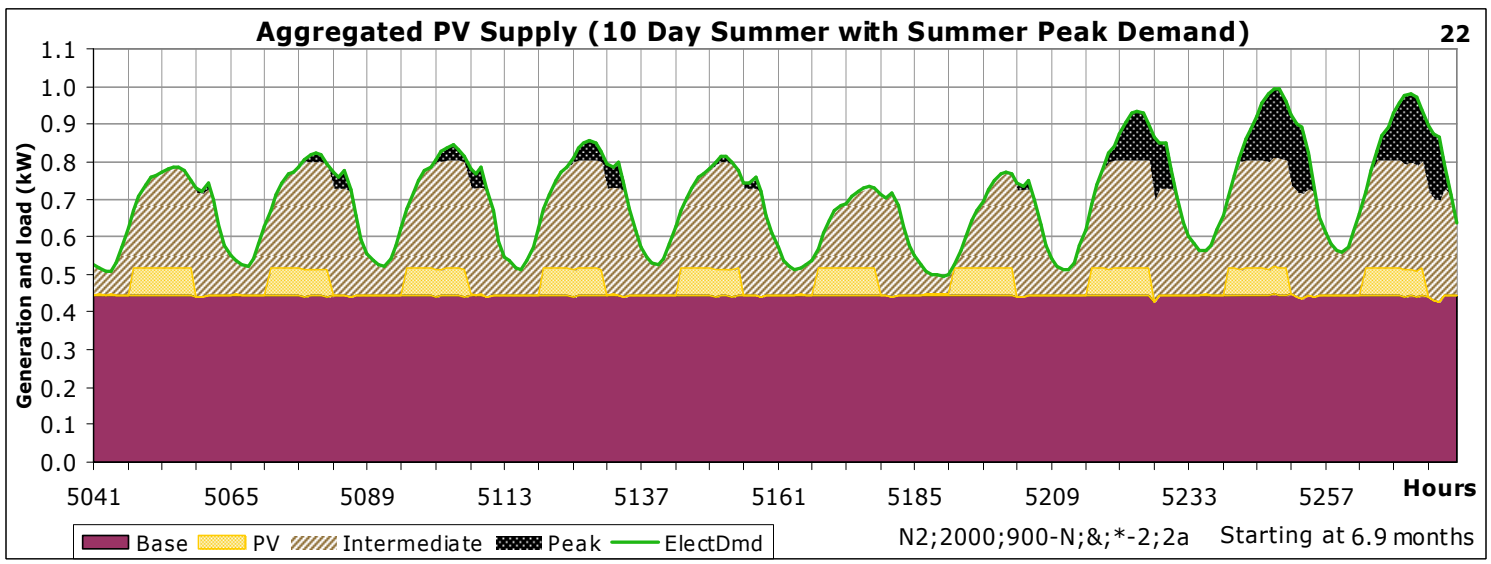




\section{c: aggregated loads and PV generation}

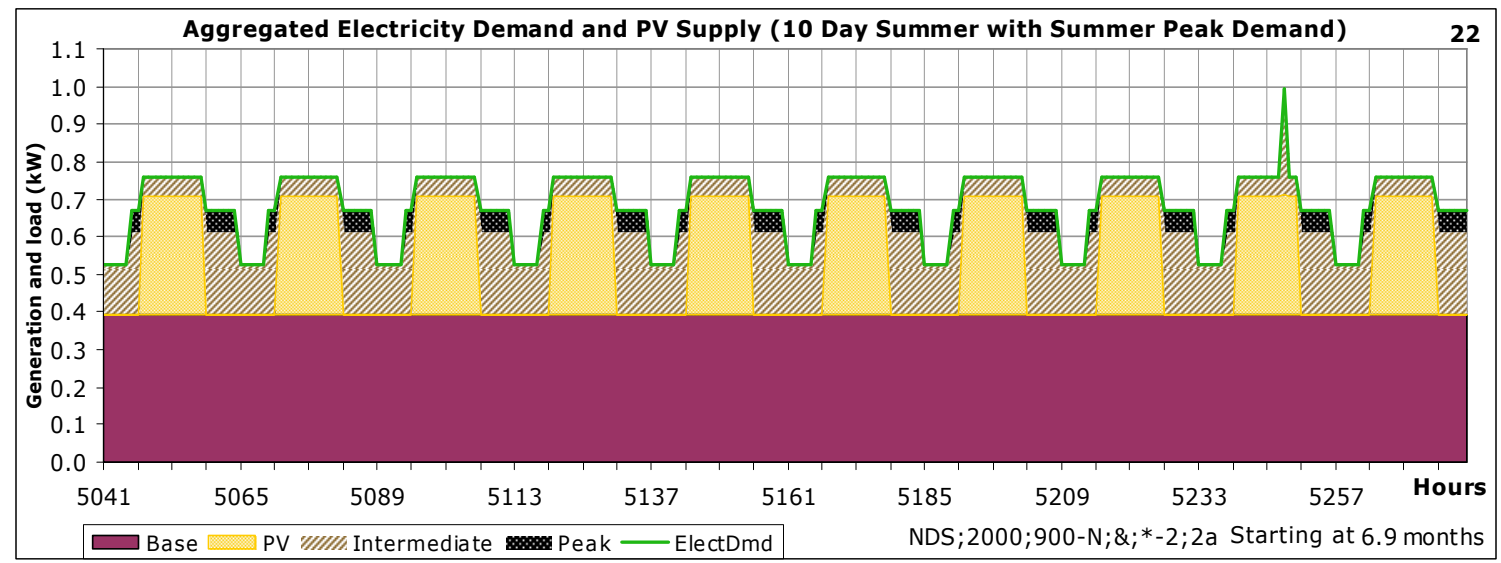

\section{Penetration of wind generation}

For each case we modeled the penetration of the intermittent generator as its cost was reduced. This gives us the trajectory of penetration and the changes in the optimal capacities of the other generators.

Figure 10 shows the penetration of the wind to the system as a function of the marginal annual cost of wind under different averaging schemes. Figure 10a shows the results based on the hour-by-hour model. Penetration starts at an annualized cost of $\$ 125$ per KWe capacity. At $\$ 80$ per KWe the total capacity was 0.6 of the system peak demand. Figure $10 \mathrm{~b}$ shows the aggregated wind supply penetration starts much earlier at $\$ 135$ per KWe capacity. At $\$ 80$ per KWe capacity the total capacity is 1.6 of the system peak demand. Figure 10c shows the results for the aggregated wind supply and electricity demand. These results are similar to the case with aggregated wind supply, at least down to about $\$ 117$ per KW which was the lowest cost used for these runs. 
Figure 10: Penetration of wind generation and optimal capacities of balance of system under various averaging schemes

a: hour-by-hour representation of load and wind generation

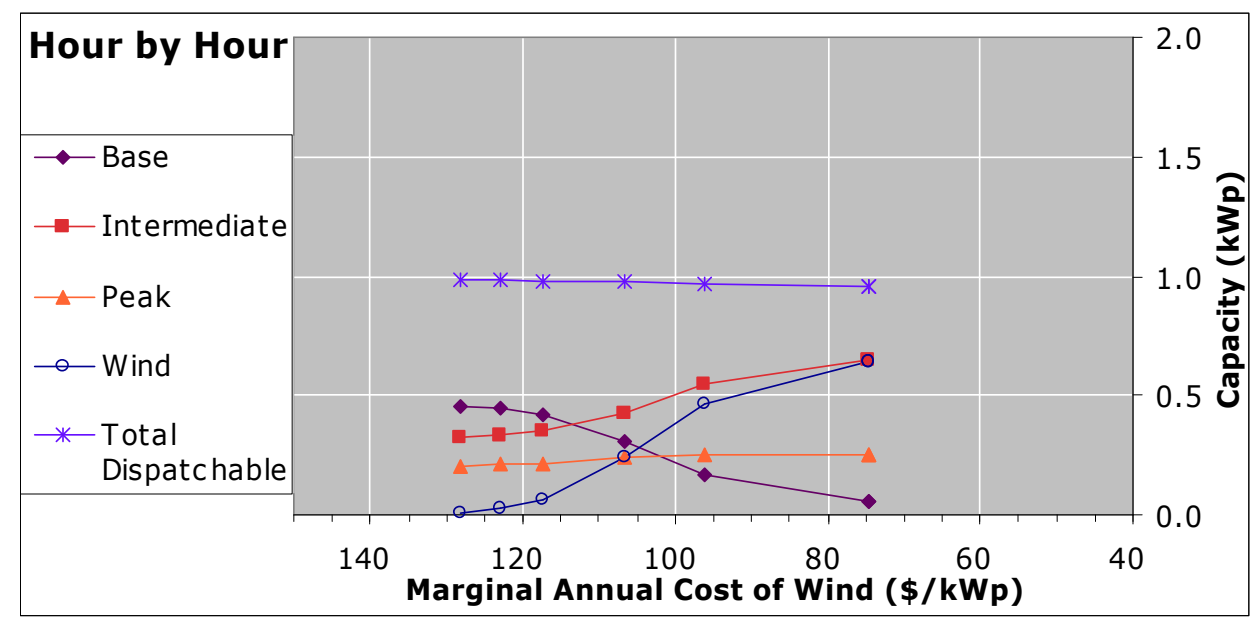

b: hour-by-hour loads with aggregated wind generation

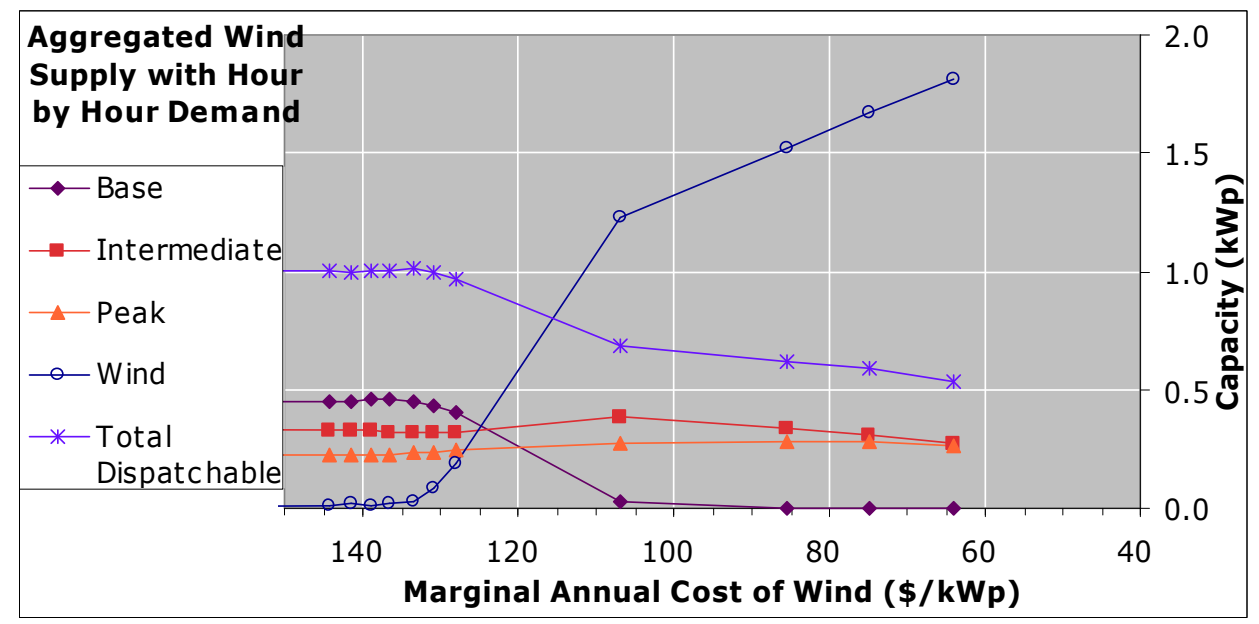




\section{c: aggregated loads and wind generation}

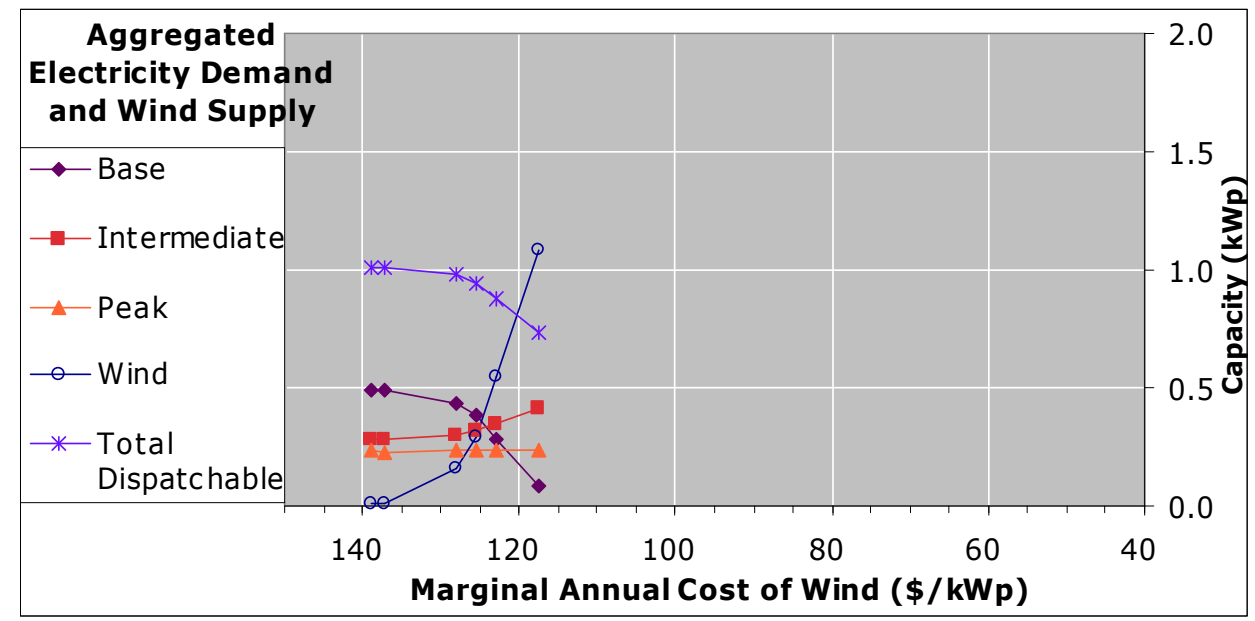

In the hour-by-hour case (Figure 10a) the wind never penetrates more than about $70 \%$ of the maximum load even at an annual cost of $\$ 75 / \mathrm{kWp}$, while in the aggregated cases the wind penetrates to a level about the maximum load at just a little less than an annual cost of $\$ 120 / \mathrm{kWp}$. In addition, in the hour-by-hour case, the total capacity of the dispatchable technologies is only slightly reduced from 1 times the system peak since the actual wind generation happens to be very low during the peak hours. In the aggregated cases, however, the dispatchable capacity declines markedly when the wind penetrates since in the aggregated case, there is substantial wind generation at the system peak. Because the wind generates at a fairly constant level and quite reliably, its value to the system is unrealistically high in the aggregated case, leading to high penetration rates.

Figure 11 plots wind penetration curves under three averaging schemes. Using the aggregated wind supply representation we see wind begins to penetrate at a much higher price than it does with the true hour-by-hour representation and it penetrates at a greater rate. We note that we see the same pattern of penetration with or without the aggregation of the electricity demands. This suggests that it is the aggregation of the wind power that affects the results, not the aggregation of the demands. 
Figure 11: Wind penetration under the different averaging schemes

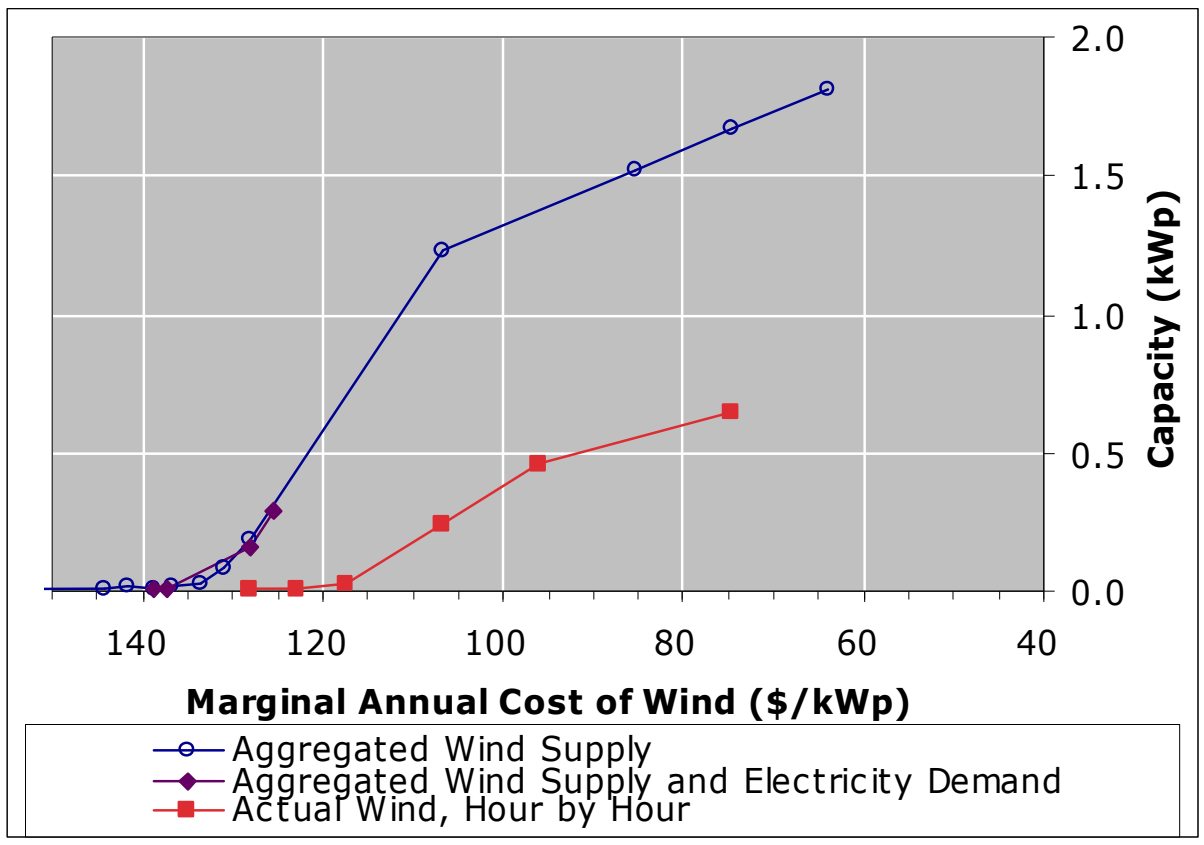

Figure 12 plots the system composition as a function of the wind capacity. Figure 12 a shows the case with hour-by-hour loads and generation. As wind penetrates the base load capacity is displaced and the intermediate capacity increases. In effect, the base load capacity is replaced by a combination of wind and intermediate capacity. In the hour-byhour case, the total dispatchable capacity is decreased only slightly as wind penetrates since there was very little wind available at the peak hour of the year.

Figure $12 \mathrm{~b}$ shows the case with aggregated generation, but hour-by-hour loads, while Figure 12c shows aggregated loads and generation. Here the base load is displaced as wind penetrates. However, the intermediate capacity only increases slightly. At the same time, the total dispatchable capacity decreases substantially. In the aggregated cases, the average wind is used during the peak day of the year, so there is significant wind power available in the peak hour allowing the total dispatchable capacity to be reduced.

The amount of wind generation is the same in all cases. This is due to the fact that the aggregation preserves the capacity factor of the wind. The major difference between the cases is the mix of baseload and intermediate generation. The displacement of the baseload generation happens more quickly in the case with hour-by-hour wind supply than the cases with aggregated wind supply since in the aggregated wind supply cases, the wind would supply less electricity during the strong wind hours due to the aggregation and the baseload generation is used to cover this part of electricity demand. 
Figure 12: Capacities of generators as a function of wind capacity for different averaging schemes

a: Hour-by-hour loads and wind generation

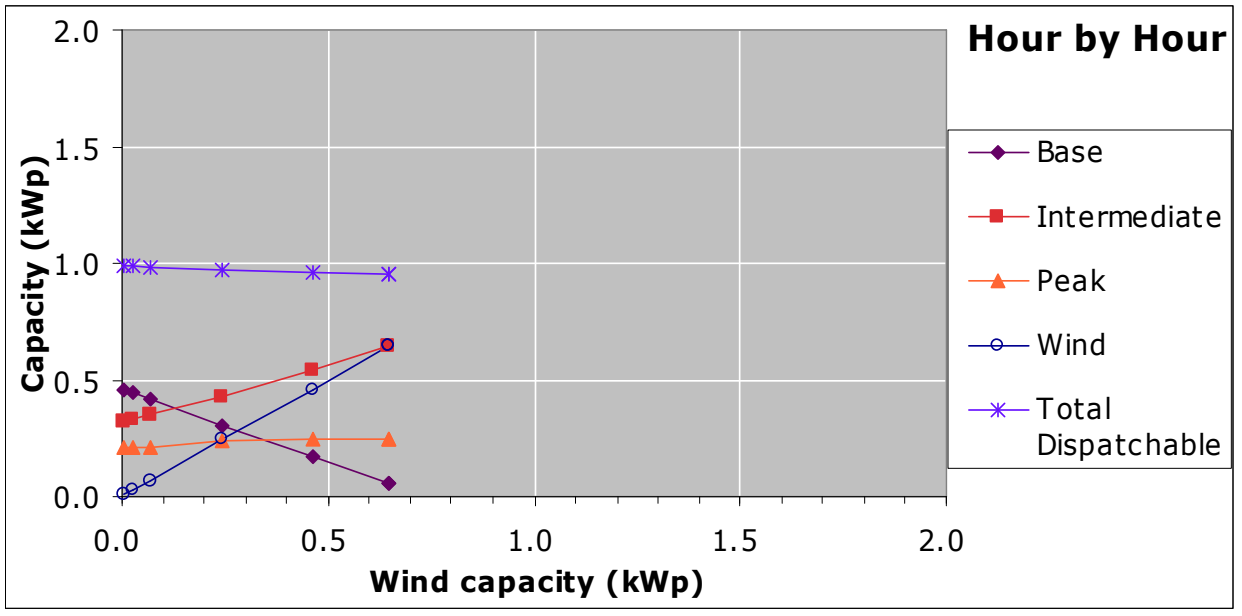

b: Aggregated wind supply with hour-by-hour loads

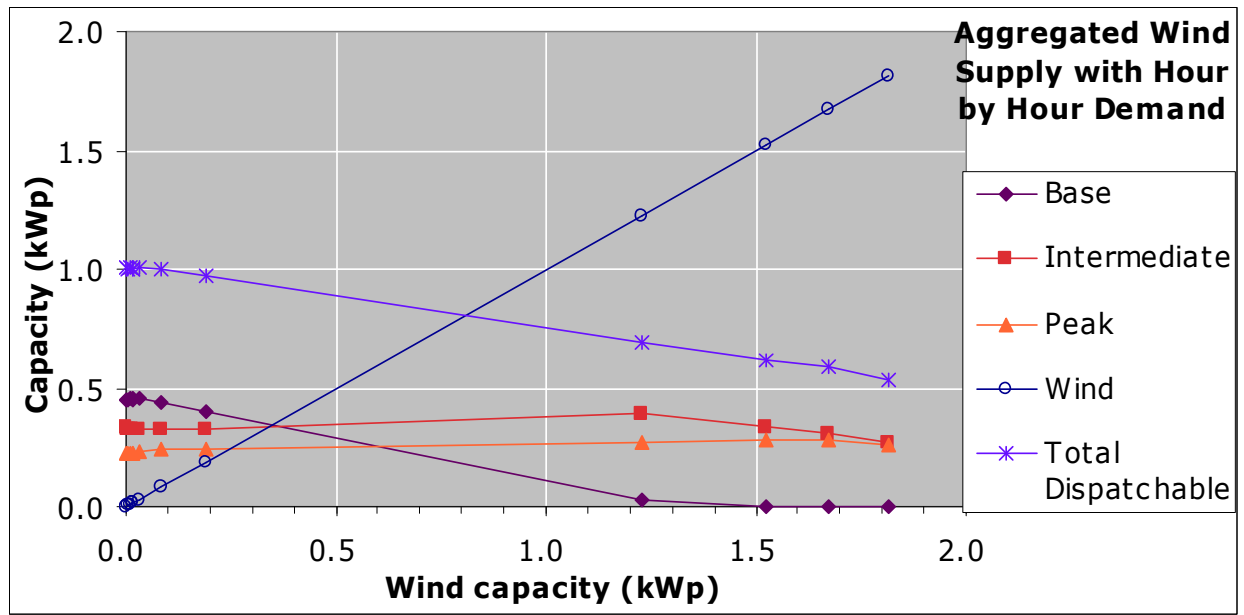


c: Aggregated wind supply and loads

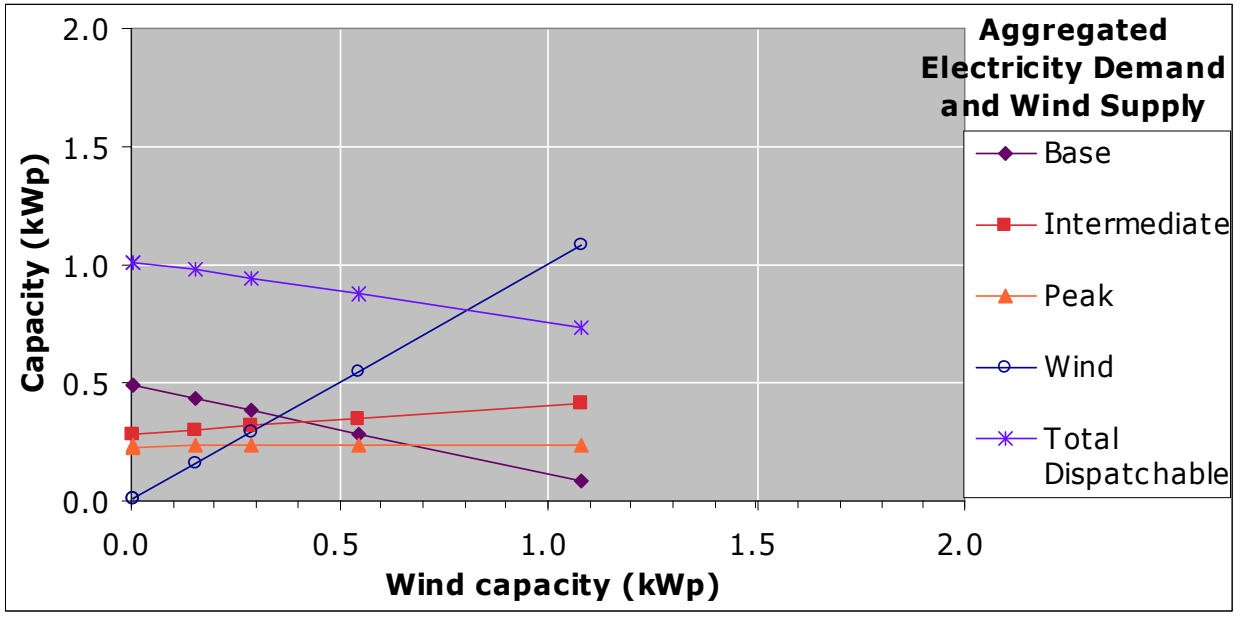

Figure 13 shows the system electricity generation as the wind penetrates the energy system for the various cases.

Figure 13: Total generation by each generator as wind penetrates the system under different averaging schemes

a: Hour-by-hour representation of wind generation and loads

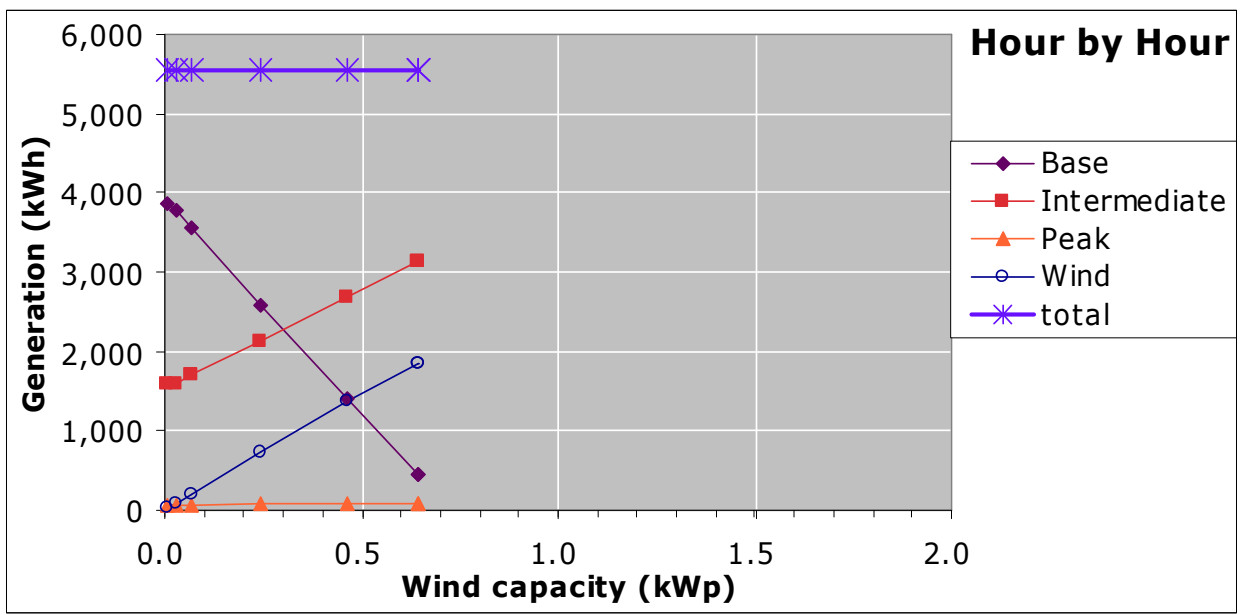




\section{b: Aggregated wind generation with hour-by-hour loads}

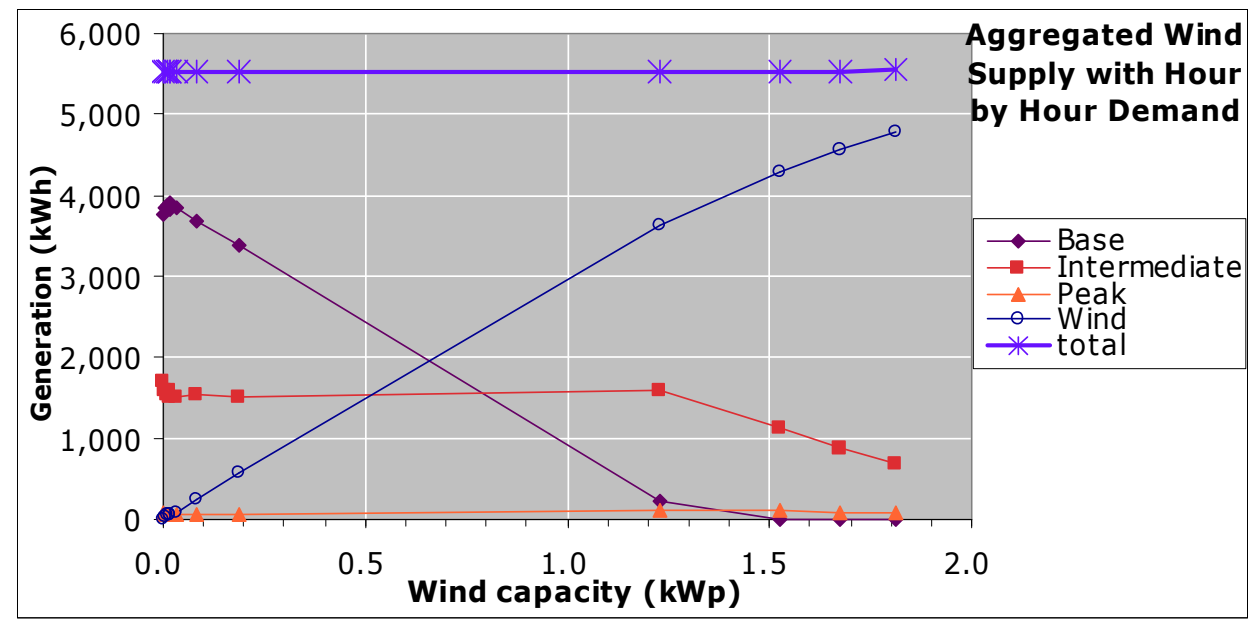

c: Aggregated wind generation and loads

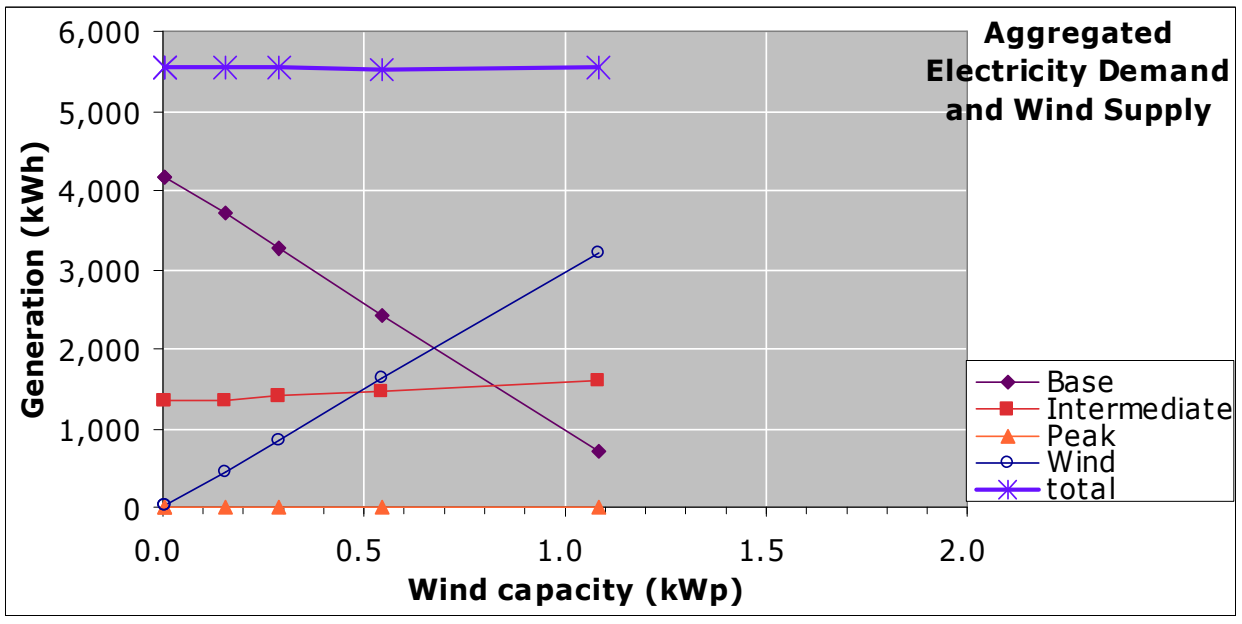

\section{Penetration of PV generators}

Figure 14 shows the penetration of the PV to the system as a function of the marginal annual cost of PV under different averaging schemes. Figure 14a shows the penetration using the hour-by-hour model. Penetration starts at an annual cost of $\$ 107$ per KWe capacity and penetrated at $\$ 67$ per KWe capacity with total capacity at 0.4 of the system peak demand. Figure 14b shows the aggregated PV supply penetration starts earlier, at $\$ 112$ per KWe capacity. Figure 14c shows aggregated wind supply and electricity demand also starts at $\$ 112$ per KWe. 
Figure 14: Penetration of $P V$ and optimal capacities of the balance of the system as a function of $P V$ cost

a: Hour-by-hour representation of loads and PV generation

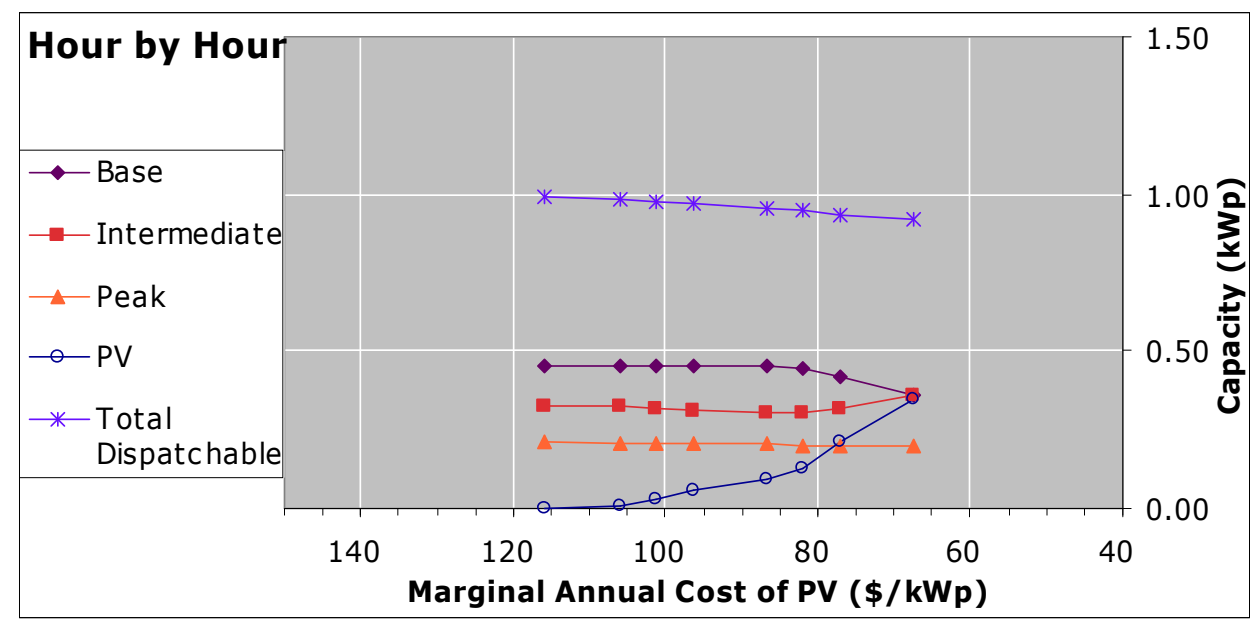

b: Aggregated representation of PV generation with hour-by-hour loads

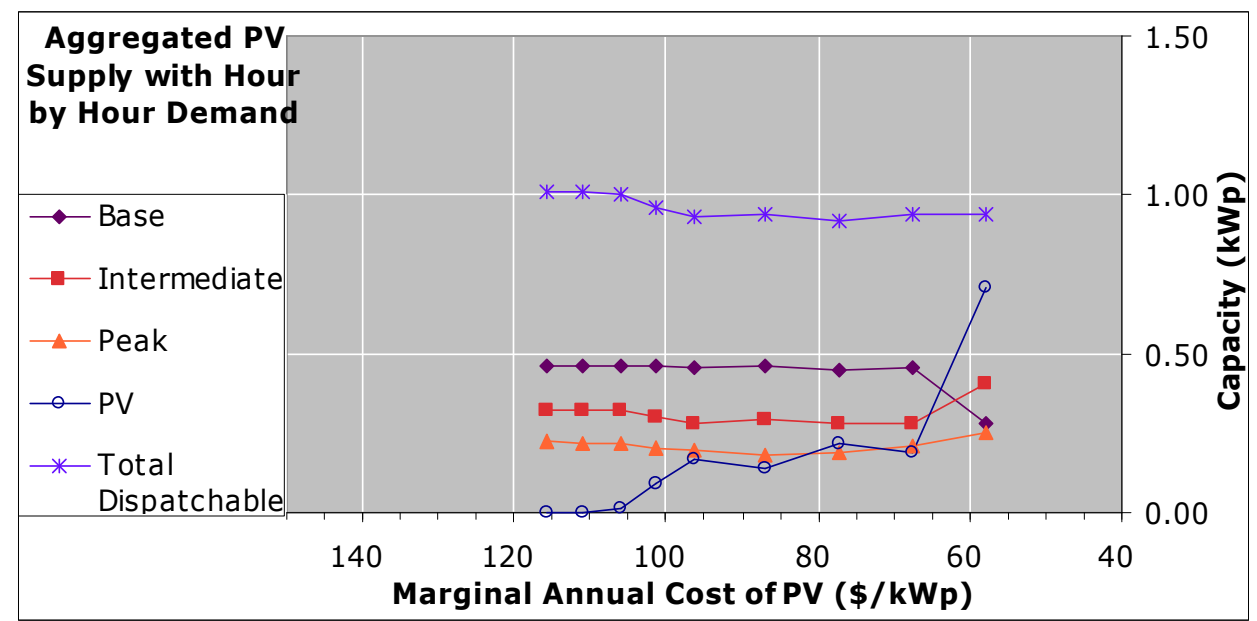




\section{c: Aggregated loads and PV generation}

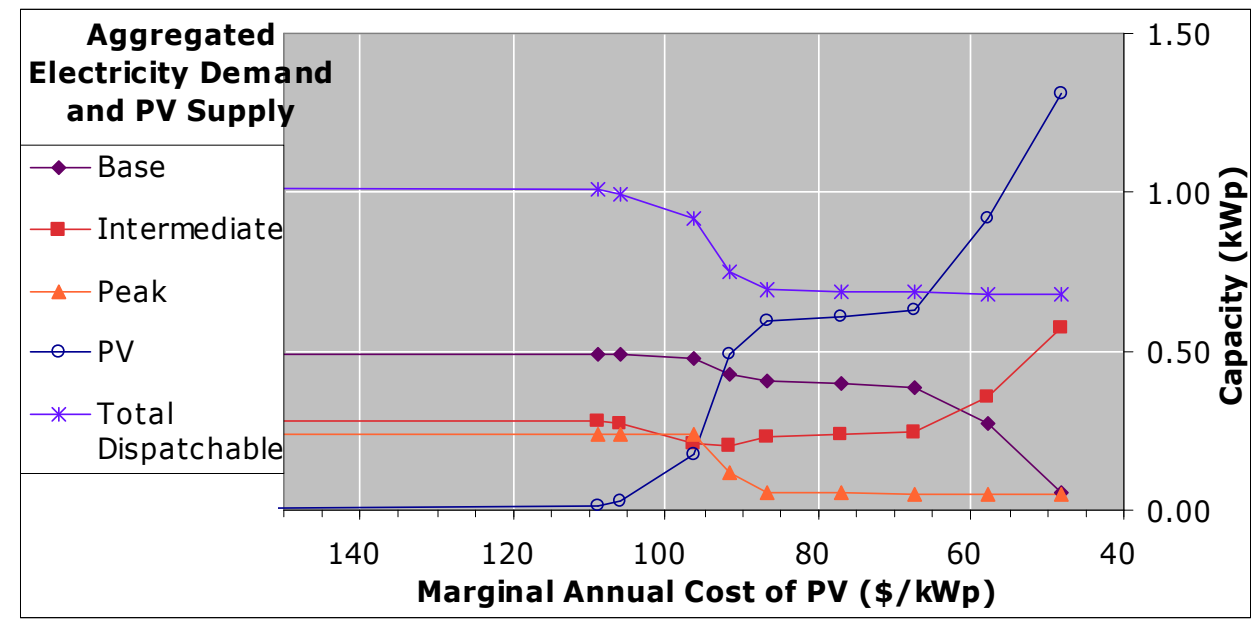

The hour-by-hour results show that PV penetrates at a low price and its capacity grows slowly as the price is reduced. In the aggregated cases penetration begins at a much higher cost and penetration jumps quickly once a threshold cost is reached. The magnitude of the jump is noticeably larger in the case where both the PV generation and the loads have been aggregated. In the case where just the PV generation has been aggregated and hour-by-hour loads are used the jump is present, but not as large. We attribute the fact that the jump is much larger in the case of aggregated loads and generation to the exact match between loads and generation when both of them are aggregated.

Figure 15 plots PV penetration curves under three averaging schemes, showing the disparity in penetration rates. 
Figure 15: PV penetration as a function of cost under the different averaging schemes

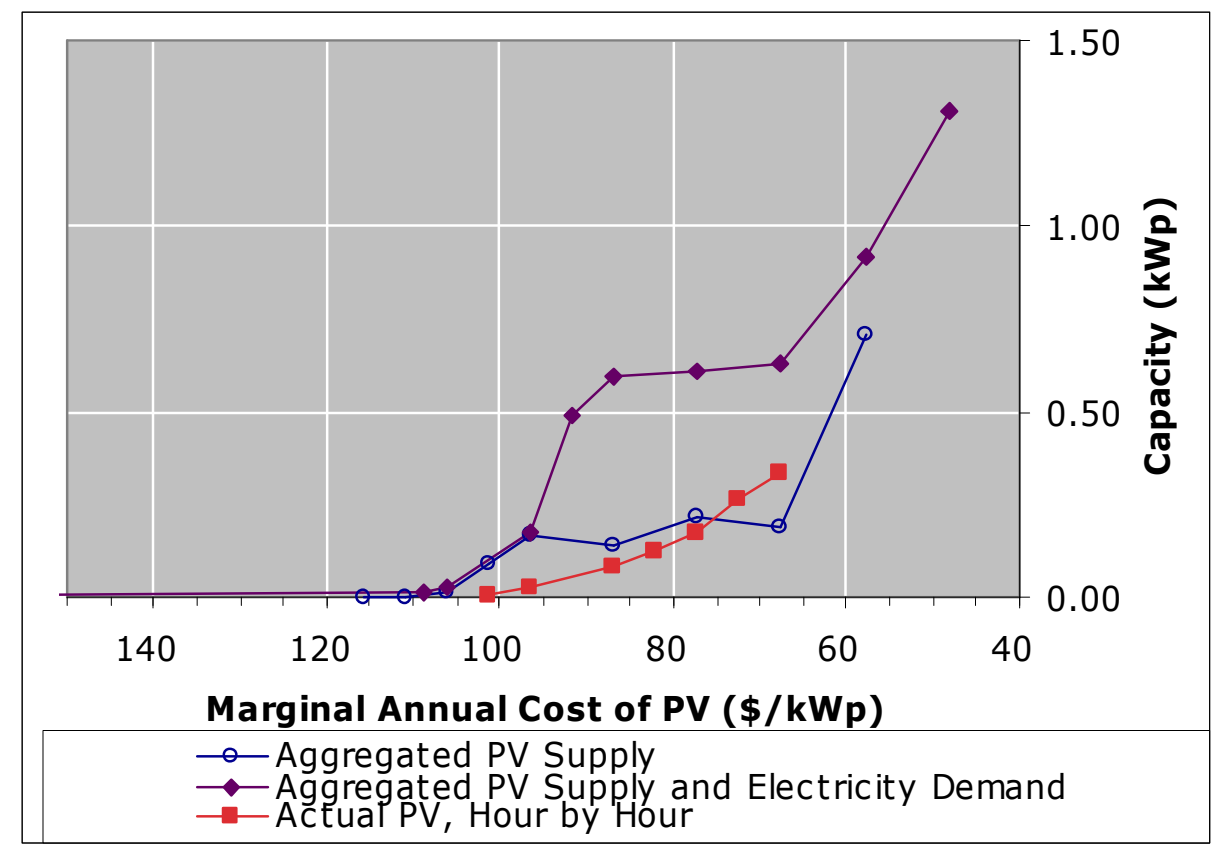

Figure 16 plots the system composition as the PV penetrates into the energy system. Figure 16a (the hour-by-hour case) and Figure 16b (the aggregated supply with hour-by-hour demands) more or less agree, out to the levels of cost used. However, Figure 16c which shows the aggregated supply and demand case is noticeably different. The total dispatchable capacity declines more rapidly due to a more rapid decline in the intermediate and peaker capacity. This is due to the fact that the patterns of the demand match the patterns of supply exactly so the PV is modeled as a very effective generator.

Figure 16: Optimal capacities of the balance of the system as PV penetrates

a: Hour-by-hour loads and PV generation

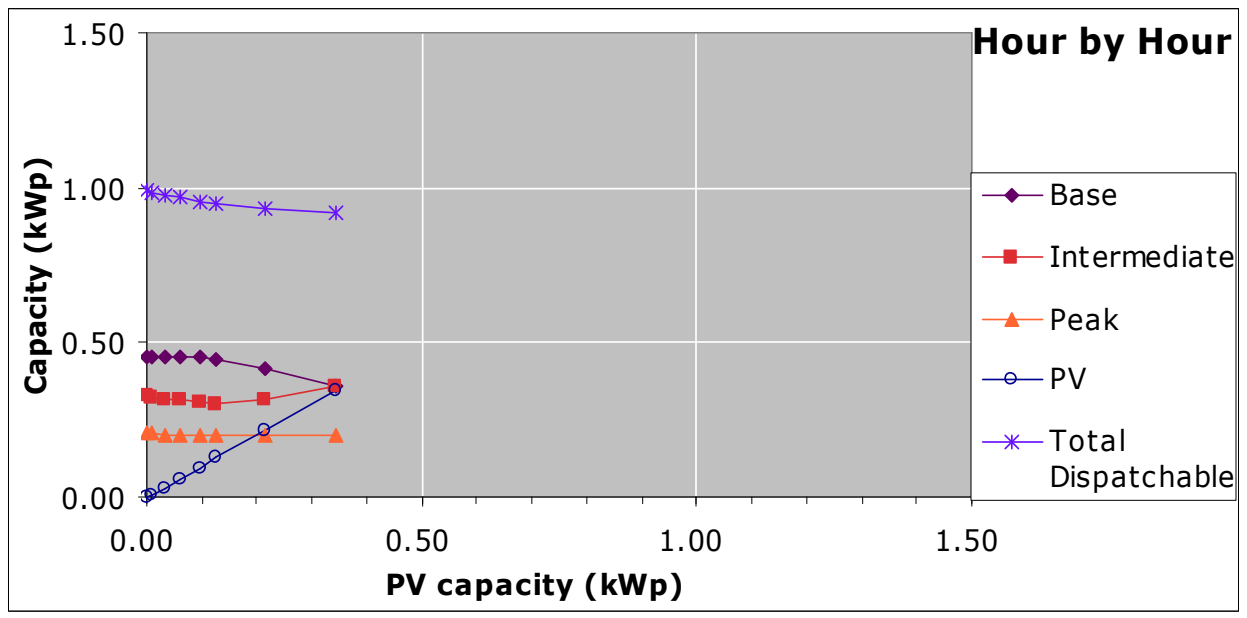




\section{b: Aggregated PV generation with hour-by-hour loads}

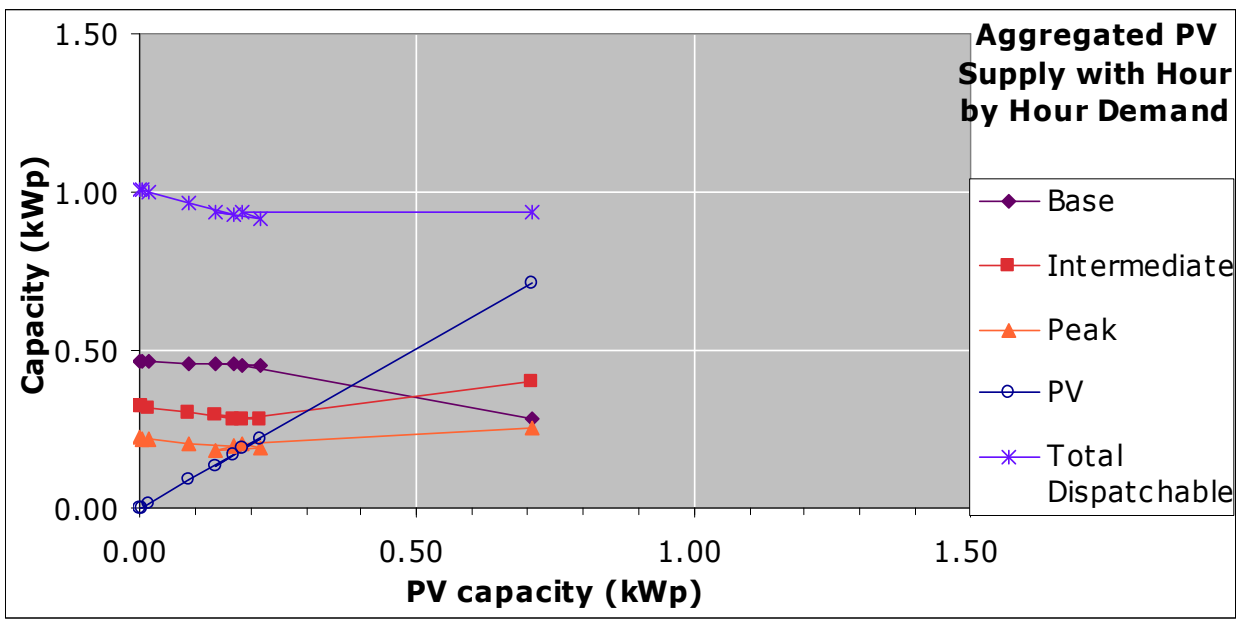

c: Aggregated loads and PV generation

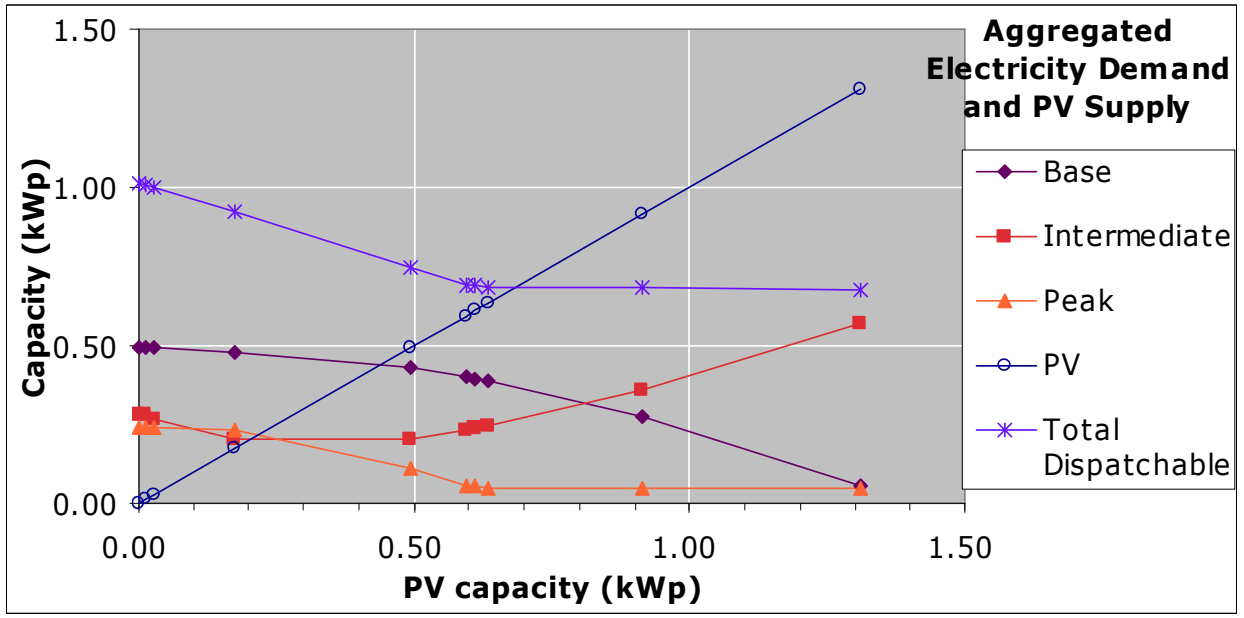

Figure 17 is the system electricity generation as the PV penetrates the energy system. 
Figure 17: Total generation by each generator as $P V$ penetrates the system a: Hour-by-hour loads and PV generation

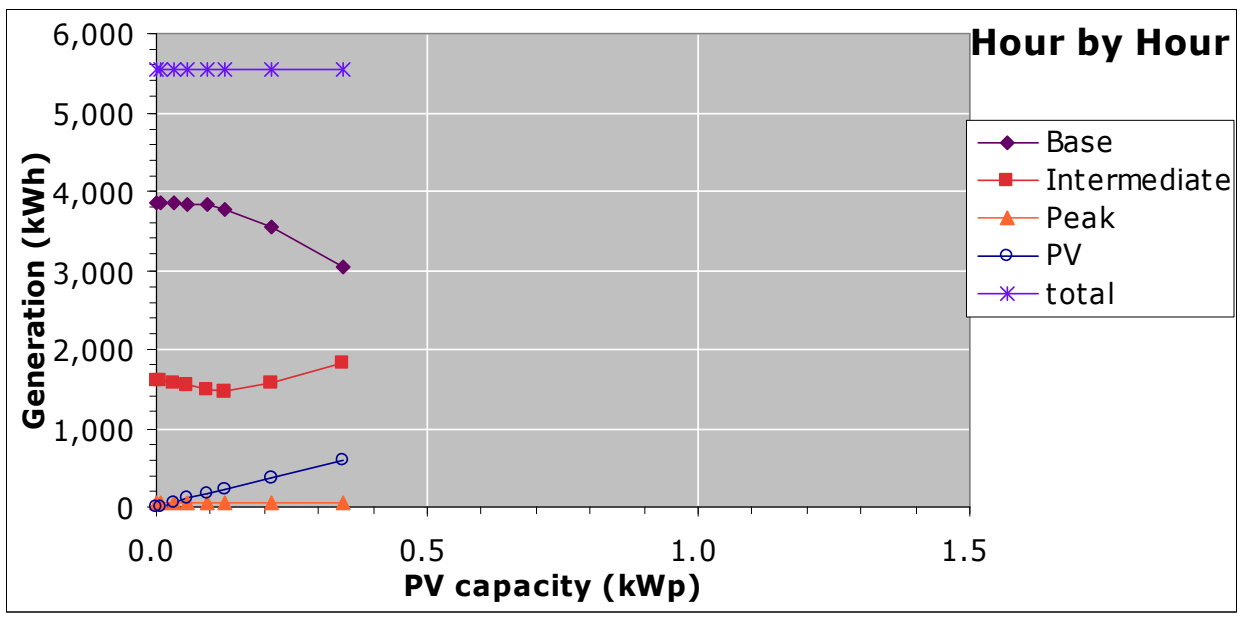

b: Aggregated PV generation with hour-by-hour loads

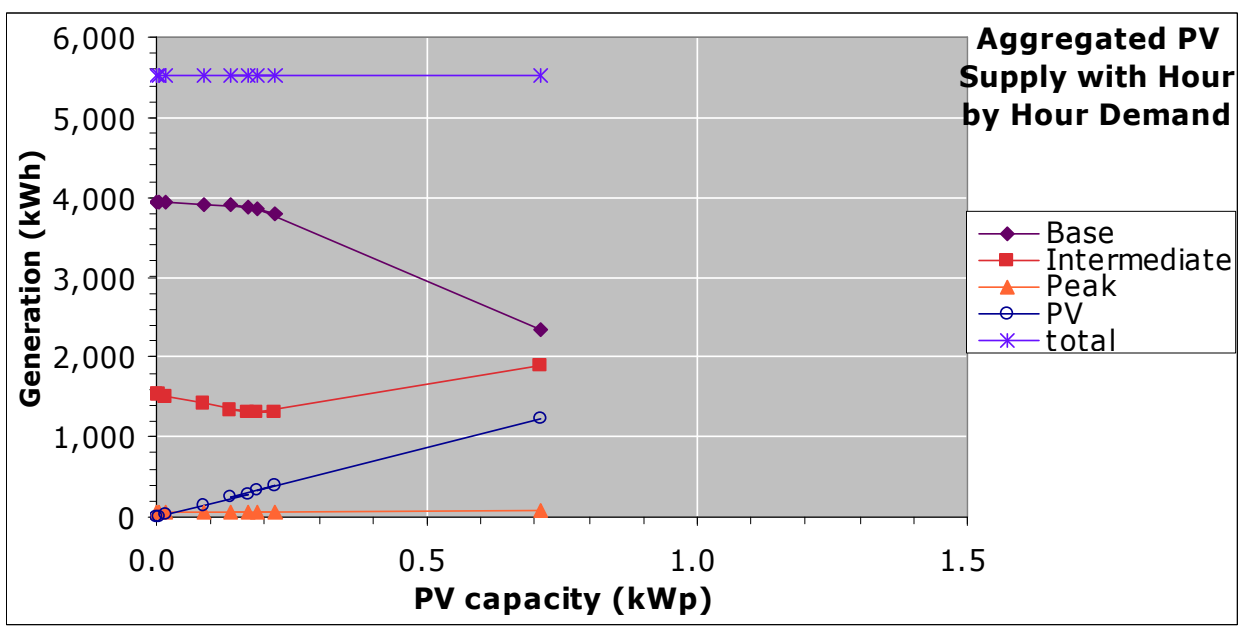




\section{c: Aggregated loads and PV generation}

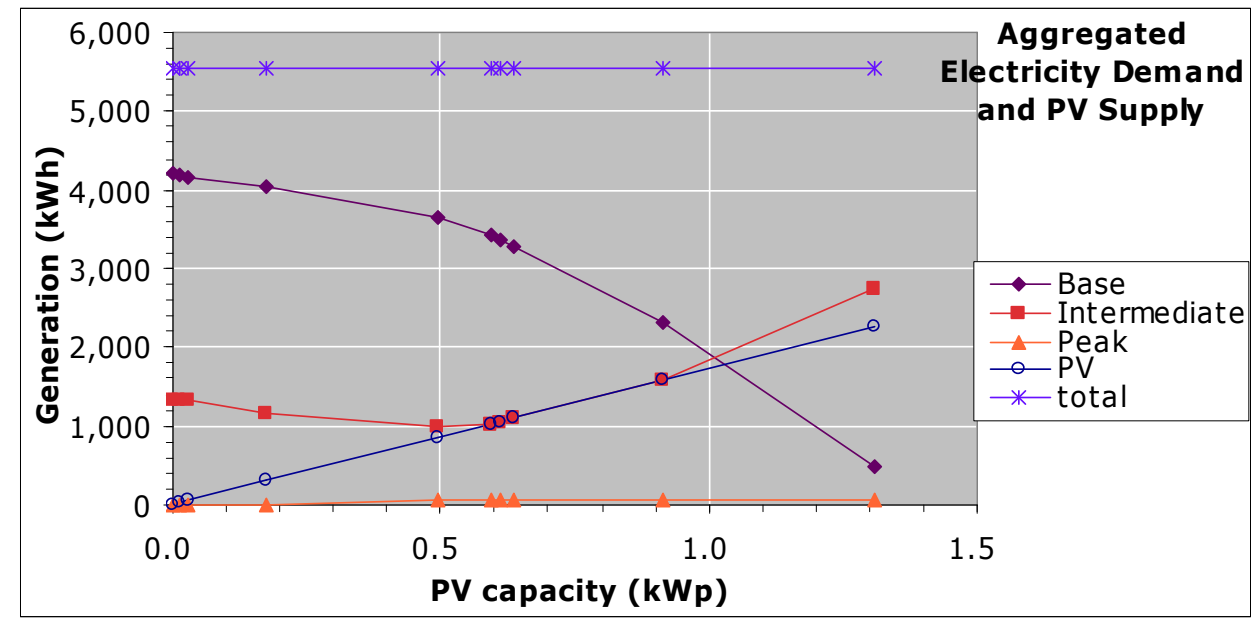

Aggregated generation represents the intermittent resources as a reliable generator with steady output. PV has significant production during all peak hours. This overvalues the intermittent generators.

\section{Conclusions}

This study shows that the method of representing the time patterns of intermittent generation technologies can have a substantial impact on the projected penetration of the intermittent and the changes in the optimal capacities of the balance of the system. The highly aggregated load duration curve approach represents the intermittents as a fairly reliable generator without large swings in output. This tends to overvalue the intermittent generator leading to higher penetration as a function of capital cost as compared to the rates seen with the hour-by-hour model. Along with this we see a higher rate of displacement of dispatchable generation capacity as the intermittent penetrates. 


\section{References}

Lamont, Alan, Long-term system benefits of intermittent electric generation technologies, Draft for review, Lawrence Livermore National Laboratory, UCRL-TR-215091-DRAFT, August, 2005

Lamont, Alan, User's guide to the META-Net Economic Modeling System, Version 1.2, Lawrence Livermore National Laboratory, UCRL-ID-122511, November 1994

Energy Information Administration (EIA), U.S. Department of Energy, The Electricity Market Module of the National Energy Modeling System, Model Documentation Report, Washington, DC 20585, DOE/EIA-M068 (2001), February 2001

Energy Information Administration (EIA), U.S. Department of Energy, Assumptions for the Annual Energy Outlook 2003, DOE/EIA-0554(2003), 2003, Table 40

California Independent Systems Operator (CAISO), OASIS data base, http://oasis.caiso.com/ (for the electricity demand data)

Jackson K., Wind power generation trends, CWEC-2003-01, California Wind Energy Collaborative, 2003 (for the wind data)

National Renewable Energy Laboratory (NREL), PV Watts:

http://rredc.nrel.gov/solar/codes algs/PVWATTS/version1/US/California/ (for the PV data) 


\section{Appendix A: The META-Net modeling system}

The Market Equilibrium and Technology Assessment Network Modeling System, META $\bullet$ Net, could be used for building and solving multi-period equilibrium energy economic models to analyze the energy system. META $\bullet$ Net models a market economy as a network of nodes representing resources, conversion processes, markets, and end-use demands. Commodities flow through this network from resources, through conversion processes and markets, to the end-users. META $\cdot$ Net then finds the multi-period equilibrium prices and quantities. The solution includes the prices and quantities demanded for each commodity along with the capacity for each conversion process.

META $\bullet$ Net solves the economic model by exchanging price and quantity information between nodes each hour. The algorithm is illustrated in Figure A1. The demand nodes send down a quantity demanded. The market nodes allocate total demand among the generators based on prices provided by the generators (generators with lower prices receive higher allocations).

When a generator's allocation is less than its capacity, it sends a price equal to its operating cost. Such a low cost can elicit a demand that exceeds the capacity of the generator. In that case, over a series of iterations the generator increases its price. As the price increases, the market allocates less demand to the generator until a price is found such that demand sent to the generator is equal to its capacity. If the market nodes are highly price sensitive, the price in a particular hour is approximately equal to the system marginal cost at that hour. Based on this, the generator can make an accurate estimate of the system marginal cost or price. From this, it can estimate the shadow value on the constraint that generation cannot exceed capacity, and, through a series of iterations, adjust its capacity until the condition all the demands are met.

This can be interpreted as a perfect market in which each supplier to a market (i.e. each generator) receives as payment the marginal cost in the market. It then can make the financial calculation as to whether or not additional increments of capacity would earn an acceptable rate of return and increase or decrease its capacity accordingly. 
Figure A1: Schematic of META-Net model

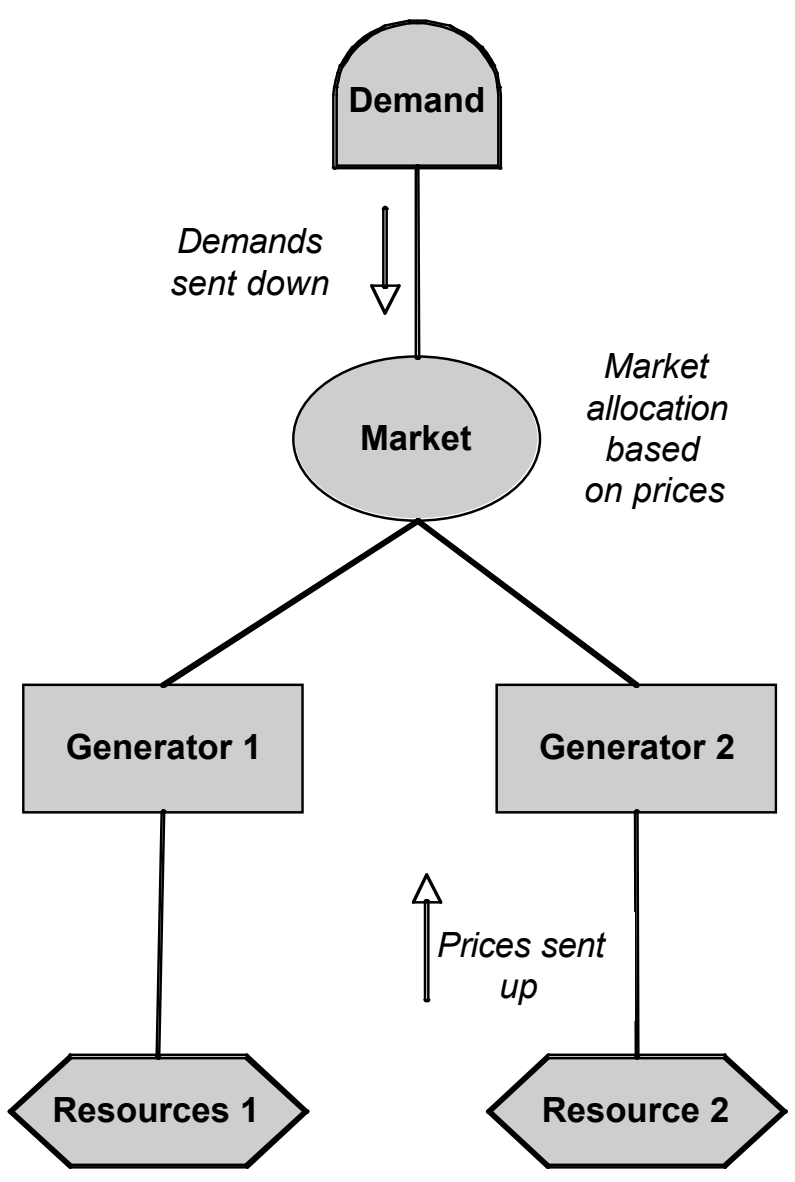




\section{Appendix B: Parameters and data for model}

Demands: data for California 2001

Wind: data from Tehachapis, California for 2001

PV data for Sacramento, California 2001 (pointed south, tilted at latitude)

Natural gas price: $\$ 6 / \mathrm{mmBtu}$

Nuclear fuel cost $4.6 \mathrm{mills} / \mathrm{kWh}$

Interest rate $10 \%$

The capital and operating costs of the technologies are given in Table B1

TableB 1: Cost parameters of technologies

\begin{tabular}{|c|c|c|c|c|c|c|c|}
\hline Technology & $\begin{array}{c}\text { Total Over- } \\
\text { night Costs } \\
(2001 \$ / k w)\end{array}$ & $\begin{array}{l}\text { Fixed } \\
\text { O\&M } \\
(2001 \\
\$ / \mathbf{k w})\end{array}$ & \begin{tabular}{|l|} 
Life \\
$($ yrs $)$
\end{tabular} & \begin{tabular}{|l|} 
Present \\
Value \\
Fixed \\
O\&M \\
cost \\
$(2001 \$$ \\
$/$ kw)
\end{tabular} & $\begin{array}{l}\text { Total } \\
\text { Capital } \\
\text { cost } \\
(2000 \$ \\
/ \mathbf{k w})^{2}\end{array}$ & $\begin{array}{l}\text { Variable } \\
\text { O\&M } \\
(2001 \$ \\
\text { mill/kwh) }\end{array}$ & $\begin{array}{l}\text { Heat } \\
\text { Rate } \\
\text { (Btu } \\
\text { /kwh) }\end{array}$ \\
\hline $\begin{array}{l}\text { Peak: } \\
\text { Advanced } \\
\text { Combustion } \\
\text { Turbine }\end{array}$ & 460 & 8.17 & 20 & 69.55 & 529.55 & 3.07 & 8550 \\
\hline $\begin{array}{l}\text { Intermediate: } \\
\text { Advanced } \\
\text { Gas/Oil } \\
\text { Combined } \\
\text { Cycle }\end{array}$ & 608 & 10.22 & 30 & 96.34 & \begin{tabular}{|l|}
704.34 \\
\end{tabular} & 2.04 & 6350 \\
\hline $\begin{array}{l}\text { Base: } \\
\text { Advanced } \\
\text { Nuclear }\end{array}$ & 2117 & 58.48 & 30 & 551.28 & 2668.28 & 0.43 & $\begin{array}{l}1040 \\
0\end{array}$ \\
\hline Wind $^{3}$ & 938 & 26.1 & 20 & 222.20 & 1160.20 & 0 & na \\
\hline $\begin{array}{l}\text { Solar } \\
\text { Photovoltaic }\end{array}$ & 3389 & 10.06 & 30 & 94.83 & 3483.83 & 0 & na \\
\hline
\end{tabular}

Source: EIA, 2003 